\title{
Two-Way Regionalized Classification of Multivariate Datasets and its Application to the Assessment of Hydrodynamic Dispersion ${ }^{1}$
}

\author{
Fernando António Leal Pacheco ${ }^{2,3}$ \\ and Paulo Milton Barbosa Landim ${ }^{4}$
}

\begin{abstract}
Zones of mixing between shallow groundwaters of different composition were unravelled by "twoway regionalized classification," a technique based on correspondence analysis (CA), cluster analysis (ClA) and discriminant analysis (DA), aided by gridding, map-overlay and contouring tools. The shallow groundwaters are from a granitoid plutonite in the Fundão region (central Portugal). Correspondence analysis detected three natural clusters in the working dataset: 1 , weathering; 2 , domestic effluents; 3, fertilizers. Cluster analysis set an alternative distribution of the samples by the three clusters. Group memberships obtained by correspondence analysis and by cluster analysis were optimized by discriminant analysis, gridded over the entire Fundão region, and converted into "two-way regionalized classification" memberships as follows: codes 1, 2 or 3 were used when classification by correspondence analysis and cluster analysis produced the same results; code 0 when the grid node was first assigned to cluster 1 and then to cluster 2 or vice versa (mixing between weathering and effluents); code 4 in the other cases (mixing between agriculture and the other influences). Code- 3 areas were systematically surrounded by code-4 areas, an observation attributed to hydrodynamic dispersion. Accordingly, the extent of code-4 areas in two orthogonal directions was assumed proportional to the longitudinal and transverse dispersivities of local soils. The results (0.7-16.8 and 0.4-4.3 $\mathrm{m}$, respectively) are acceptable at the macroscopic scale. The ratios between longitudinal and transverse dispersivities (1.2-11.1) are also in agreement with results obtained by other studies.
\end{abstract}

KEY WORDS: correspondence analysis, cluster analysis, discriminant analysis, surface mapping tools, regionalized classification, hydrodynamic dispersion.

\section{NOTATION}

Below is the alphabetical list of mathematical symbols used throughout this paper.

\footnotetext{
${ }^{1}$ Received 19 July 2002; accepted 27 October 2004.

${ }^{2}$ Geology Department, Trás-os-Montes and Alto Douro University, 5000 Vila Real, Portugal; e-mail fpacheco@utad.pt

${ }^{3}$ Geophysical Center, Coimbra University, 3000 Coimbra, Portugal.

${ }^{4}$ Applied Geology Department, São Paulo State University, Rio Claro campus, 13506-900 Rio Claro (SP), Brazil.
} 


\section{Latin Symbols}

$d$

$D\left(D_{\mathrm{L}}, D_{\mathrm{T}}\right) \quad$ Coefficient of hydrodynamic dispersion (longitudinal and transverse)

$E_{i}$

$f_{i}(\mathbf{x})$

$F \quad$ factor

classification score of group $i$

$\operatorname{grad}(h) \quad$ hydraulic gradient

$h \quad$ number of rows along the height of a grid

$k \quad$ number of groups present in a multivariate site-related dataset

$K \quad$ hydraulic conductivity

$l \quad$ number of columns along the width of a grid

$m_{\mathrm{t}} \quad$ total porosity

$m_{\mathrm{e}} \quad$ effective porosity

$n$

$p$

$\operatorname{prob}_{i} \quad$ prior probability of group's $i$ membership

$\operatorname{Prob}_{i} \quad$ posterior probability of group's $i$ membership

S

$t$

$v$

matrix of within-group variances and covariances

time

velocity of a solute dissolved in water along the mean direction of

flow

$\boldsymbol{x}_{p} \quad$ vector containing the values of the $p$ original (or $X$ ) variables

$\mathbf{x}^{\prime} \quad$ transpose of $\mathbf{x}$

$\overline{\mathbf{x}} \quad$ mean of $\mathbf{x}$

$\overline{\mathbf{x}}^{\prime} \quad$ transpose of $\overline{\mathbf{x}}$

$X \quad$ set of original variables in the working dataset

$w_{i j} \quad$ loading of variable $j$ in factor $i$

$w \%$ hydrochemical parameter discriminating between waters with

pollution weathering-dominated chemistries and waters with chemistries controlled by anthropogenic inputs

$w \%-$

agriculture

hydrochemical parameter discriminating between waters with fertilizer-dominated chemistries and effluents-dominated chemistries

\section{Greek Symbols}

$\alpha\left(\alpha_{\mathrm{L}}, \alpha_{\mathrm{T}}\right) \quad$ mechanical dispersivity (longitudinal and transverse)

$\delta \quad \log$ standard deviation of a grain size distribution

$\gamma \quad$ identification code of a hybrid region

$\sigma \quad$ standard deviation of a membership probability distribution

$\psi \quad$ specific retention of a porous material 


\section{INTRODUCTION}

Regionalized classification (RC) is defined as the probabilistic assignment of sites to groups by using discriminant analysis (DA). Following Olea (1999) and his predecessors Harff and Davis (1990), we see nothing conceptually new in RC but agree that some novelty is introduced by this joint application of a number of well-known mathematical, statistical and geostatistical techniques.

The start of $\mathrm{RC}$ requires a training set that usually is provided by cluster analysis (ClA). However, with conventional clustering algorithms the number of groups $(k)$ is defined subjectively, either on the basis of external information or iteratively until a certain function is optimized. A second difficulty in applying RC is the assignment of sites to groups when probabilities are similar among clusters. Again, the problem is solved by assigning to group zero (i.e. by setting to hybrid) all sites for which the difference between the two highest probabilities are less than a pre-established (subjective) threshold.

The primary objective of this study is to clean RC from the reported drawbacks. To define $k$ objectively we propose that it is selected by natural clustering. To identify the hybrid sites precisely, we propose that a RC based on the natural groupings (first-way RC) is combined with another RC based on the ClA groupings (second-way RC). By looking simultaneously at two different perspectives of a same reality, we expect that the typical sites maintain their group memberships no matter which clustering method is used, whereas the atypical ones alternate among groups when the clustering technique is changed. Consequently, the atypical sites are recast as hybrid sites and demarcated on a map as hybrid regions.

The spatial relation between true and hybrid regions of groundwater datasets may, in some cases, unravel the mixing between waters of different compositions. The distribution of membership probabilities within regions of fertilizerdominated water chemistries resembles the distribution of solutes inside pulselike contaminant plumes. Using the appropriate contaminant transport models, it is possible to quantify processes such as hydrodynamic dispersion from solute distributions inside plumes. As a secondary objective we wished to assess hydrodynamic dispersion across the soils of our study area (Fundão region, central Portugal) using the membership distributions as analogs for solute distributions.

\section{THE TWO-WAY RC APPROACH}

The flowchart in Figure 1 summarizes the method of two-way RC. The sites of a multivariate database are initially assigned to $k$ groups by natural clustering, and then the groups are interpreted in terms of controlling sources and/or processes. When working with groundwater databases, the selected method of natural clustering can be the RST algorithm used by Pacheco and Van der Weijden (1996), Pacheco (1998a) or Pacheco and others (1999), or can be the technique based on 


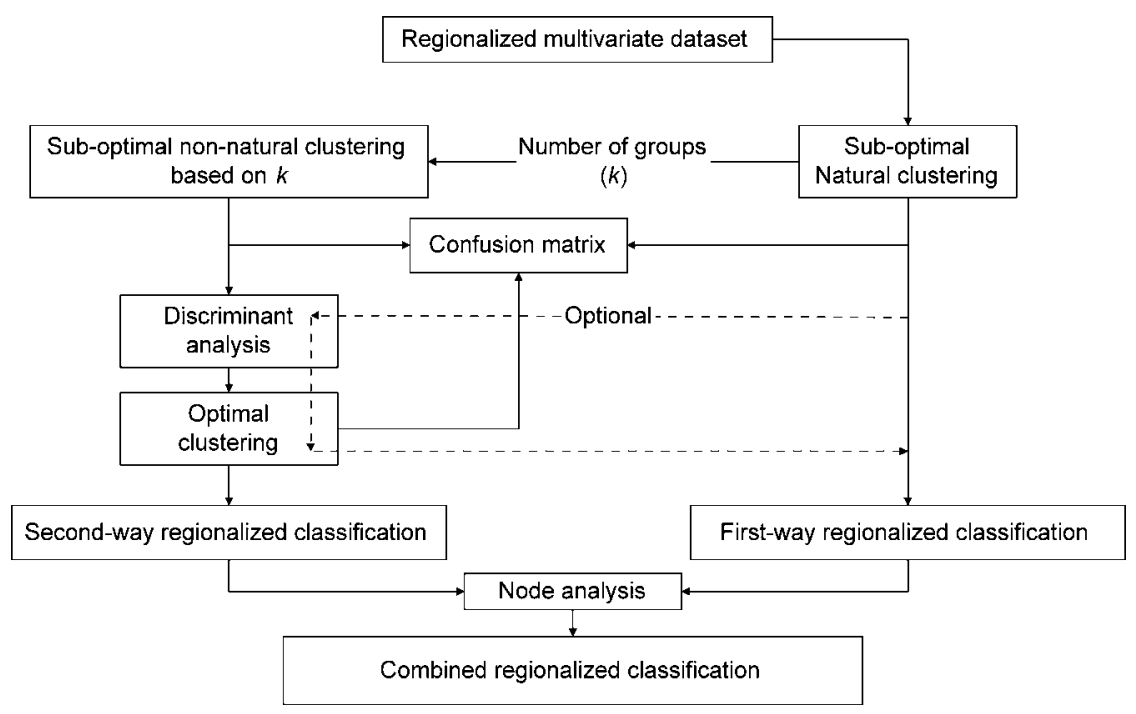

Figure 1. Flowchart illustrating two-way regionalized classification of multivariate datasets.

correspondence analysis (CA) that Pacheco (1998b) developed. The first-way RC can pass through an optimization process using discriminant analysis or terminates. To start the second-way RC we run a conventional clustering algorithm like Ward's method (1963) to obtain a sub-optimal non-natural distribution of the sites by the $k$ groups that subsequently is optimized using DA. Node analysis (NA) is a last step in two-way RC whereby the natural and non-natural group memberships are interpolated over grids of regularly spaced nodes. Nodes are then compared among grids, maintaining their original assignments or being reclassified as hybrid in a combined grid. Finally, constant membership contours are drawn across the study area that work as boundaries between different groups as well as between groups and hybrid regions.

The next sections outline the mathematical, statistical and geostatistical procedures involved in two-way RC. Detailed and more mechanically oriented descriptions of these methods are beyond the scope of this paper and can be found elsewhere (Kaufman and Rousseeuw, 1990; Jackson, 1991; Jobson, 1992; among many other neat textbooks). It also should be mentioned that we used Pacheco's (1998b) approach to CA to define the natural clusters and Ward's method to represent the technique of non-natural clustering.

\section{Correspondence Analysis}

In this study, CA is used as a natural clustering technique. The set of $p$ original or $X$ variables are first transformed onto a set of $p$ factors or $F$ variables 
in a manner that a major portion of the data variation is concentrated on just a few of the latter, the so-called $k$ common factors. The relation between the $F$ and $X$ variables is then set on the basis of a linear equation:

$$
F_{i}=w_{i 1} X_{1}+w_{i 2} X_{2}+\cdots+w_{i p} X_{p}
$$

If the signs of factor loadings ( $w_{i}$ coefficients) are equal, the corresponding $X$ variables are correlated positively in $F_{i}$, otherwise they are correlated negatively. From the observation of these "sympathies" and "antipathies" among signs of factor loadings, Equation (1) may be rewritten in forms that encompass some physical or chemical meaning. That was the approach used by Pacheco (1998b). Working with a shallow groundwater database from a granitoid plutonite (Fundão, central Portugal), he separated waters with weathering-dominated chemistries from waters with compositions controlled by anthropogenic inputs, using the following hydrochemical parameter:

$$
w \%-\text { pollution }=\frac{\text { pollution }}{\text { weathering }+ \text { pollution }} \times 100,
$$

where

$$
\begin{aligned}
& \text { pollution }=w_{1, \mathrm{Cl}}\left[\mathrm{Cl}^{-}\right]+w_{1, \mathrm{SO}_{4}}\left[\mathrm{SO}_{4}{ }^{2-}\right]+w_{1, \mathrm{NO}_{3}}\left[\mathrm{NO}_{3}^{-}\right] \\
& \text {weathering }=w_{1, \mathrm{HCO}_{3}}\left[\mathrm{HCO}_{3}^{-}\right]+w_{1, \mathrm{SiO}_{2}}\left[\mathrm{SiO}_{2}\right] .
\end{aligned}
$$

Square brackets denote molar concentrations of chloride, sulphate, nitrate, bicarbonate and silica in a spring. Springs with $w \%$-pollution less than $50 \%$ have weathering-dominated water chemistries and springs with $w \%$-pollution greater than $50 \%$ have pollution-dominated water chemistries. The extent to which each component contributes to $w \%$-pollution is determined by the $w_{1}$ values. Contaminated spring waters were further linked to sources such as farmland fertilizers or domestic effluents by the following hydrochemical parameter:

$$
w \%-\text { agriculture }=\frac{\text { agriculture }}{\text { dom. effluents } / \text { atm. input }+ \text { agriculture }} \times 100,
$$

where

$$
\begin{aligned}
& \text { agriculture }=w_{2, \mathrm{SO}_{4}}\left[\mathrm{SO}_{4}{ }^{2-}\right]+w_{2, \mathrm{NO}_{3}}\left[\mathrm{NO}_{3}^{-}\right] \\
& \text {dom. effluents/atm. input }=w_{2, \mathrm{Cl}}\left[\mathrm{Cl}^{-}\right] .
\end{aligned}
$$


Springs with $w \%$-agriculture greater than $50 \%$ were assigned to agricultural activities and springs with $w \%$-agriculture less than $50 \%$ were attributed to urban pollution plus atmospheric inputs.

In total, the hydrochemical parameters defined above accounted for about $80 \%$ of the system variance. The bi-univocal association (extent and significance) between hydrochemical parameters and factors was checked by multiple linear regression (MLR) with satisfactory results. Because the Fundão's spring water chemistries have been explained by three different sources (weathering, agriculture and domestic effluents), Pacheco (1998b) classified his dataset as a system of triple influence. In this study, these sources or influences provide a value for $k$, the number of natural clusters feeding Ward's method of ClA.

\section{Cluster Analysis (Ward's Method)}

$\mathrm{ClA}$ in this study is used as an alternative clustering technique. The adopted Ward's method (1963) belongs to the category of agglomerative hierarchical methods. The aggregate is gradually built on a similarity coefficient between samples or sites. First the algorithm gathers all most-similar pairs and then aggregates the other samples/sites or already-formed groups according to their similarities until $k$ groups are formed. Distinct from other hierarchical methods, Ward's method is a minimum variance agglomerative technique because the two clusters to be joined in each round of clustering are those generating the smallest increase in the within-cluster variation.

\section{Discriminant Analysis}

For the present case study, DA is used as a classification tool, namely for optimizing the location of sites pre-assigned by $\mathrm{CA}$ or $\mathrm{ClA}$. A general approach to the problem of (re)classifying an observation $\mathbf{x}$ may be stated as follows:

$$
E_{i}=\mathbf{x}^{\prime} \times \mathbf{S}^{-1} \times \overline{\mathbf{x}}_{i}-\frac{1}{2} \overline{\mathbf{x}}_{i}^{\prime} \times S^{-1} \times \overline{\mathbf{x}}_{i}+\ln \left(\mathrm{prob}_{i}\right), \quad i=1,2, \ldots, k
$$

where $E_{i}$ is the classification score of group $i ; \mathbf{x}^{\prime}$ the transpose of $\mathbf{x} ; \overline{\mathbf{x}}_{i}$ and $\overline{\mathbf{x}}_{i}^{\prime}$ are the mean of group $i$ observations and the transpose of that vector, respectively; $\mathbf{S}^{-1}$ the inverse of the within-group variance-covariance matrix; prob $_{i}$ the prior probability of group membership manifest in the observed $n_{i} / n$ proportion, where $n_{i}$ is the number of observations in group $i$ and $n$ the number of observations in the dataset. According to this criterion, an observation $\mathbf{x}$ will be (re)classified into the group for which the $E$ value is highest. The new (posterior) probability of group 
membership $\left(\operatorname{Prob}_{i}\right)$ is given by:

$$
\operatorname{Prob}_{i}=\frac{\operatorname{prob}_{i} \times f_{i}(\mathbf{x})}{\sum_{i=1}^{k} \operatorname{prob}_{i} \times f_{i}(\mathbf{x})}
$$

where $f_{i}(\mathbf{x})$ is the score of $\mathbf{x}$ in the frequency curve of group $i$. The relation between prior and post assignments is frequently reported in a confusion matrix that shows the number of correctly classified cases in the main diagonal and the number of misclassified cases in the off-diagonals. Confusion matrices are also useful to compare classification results obtained by different approaches [Eqs. (2) and (3), and Ward's method].

\section{Node Analysis}

The scope of NA, as employed in this study, is threefold. First we looked at this procedure as a gridding tool. Using methods such as kriging, gridding produces a regularly spaced array of $z$ values from randomly spaced $(x, y, z)$ observation points. When the $(x, y, z)$ observations are spaced randomly over the study area, there are usually many holes in their distribution. Gridding fills in the holes by extrapolating or interpolating $z$ values in those locations where no data exists. We interpolated the CA/DA group memberships to be used in NA over a grid with $l \times h$ nodes, where $l$ is the number of columns along the width and $h$ the number of rows along the height of the study area, and did the same with the ClA/DA results. After gridding we compared nodes between the $\mathrm{CA} / \mathrm{ClA}$ or one-way $\mathrm{RC}$ grids and constructed a combined or two-way RC grid. If the membership of a node was equal in the first grids, then the node stayed in its group in the combined grid. Otherwise the node was reclassified as group $-\gamma$ node (hybrid), where $\gamma$ is an arbitrary identification code. In the last stage of NA we drew constant membership contours across the grids that became boundaries between different groups and between groups and hybrid regions.

\section{THE TWO-WAY RC MODEL FOR THE FUNDÃO AREA}

In this study we used the set of 160 spring water samples that were collected in the Fundão area (central Portugal) by Van der Weijden and others (1983). The sampling was carried out in June-July. The samples' locations are plotted in Figure 2 and the chemical analyses are given in the Appendix. 


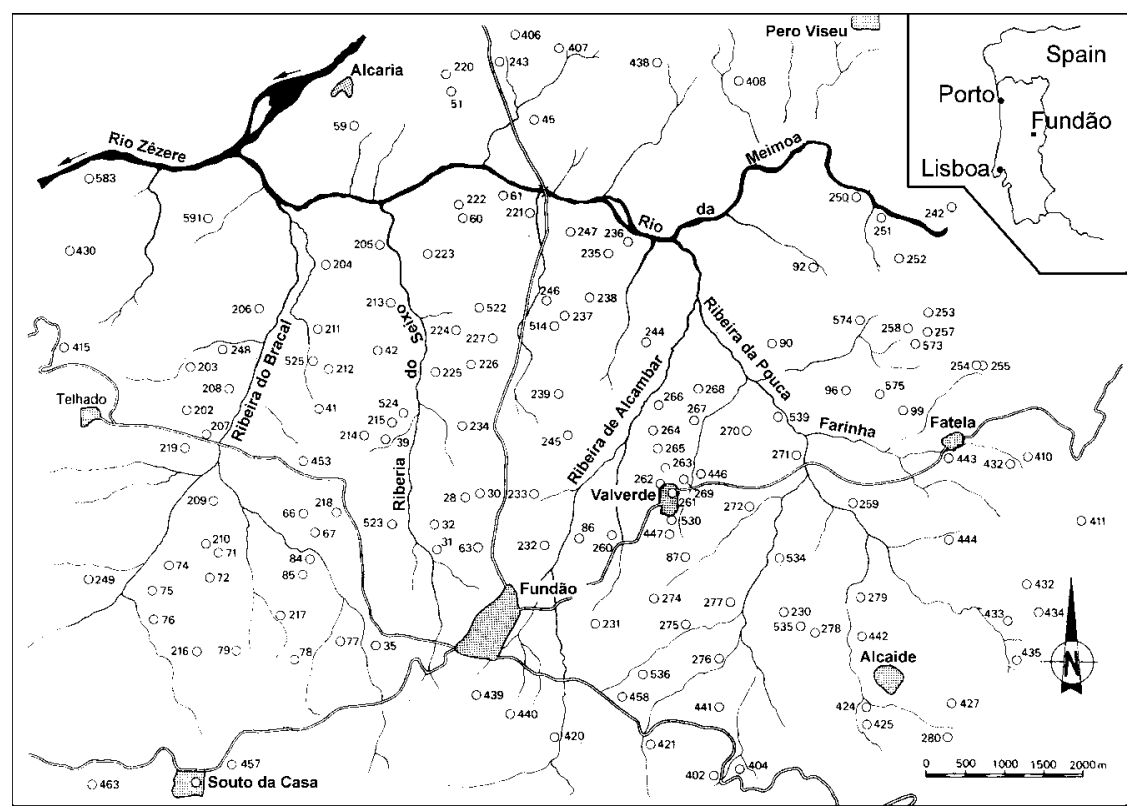

Figure 2. Location of the Fundão area and water sampling sites. Adapted from Pacheco (1998b). Original drawings in Van der Weijden and others (1983).

\section{Results of CA/DA}

CA was applied by Pacheco (1998b) to the Fundão dataset using the major anions and dissolved silica as variables (concentrations in $\mu \mathrm{mol} / \mathrm{L}$ ). The results are shown in Table 1.

From the observation of sympathies and antipathies between factor loadings, the first two factors were represented by:

- the $w \%$-pollution (factor 1), with pollution $=443.0\left[\mathrm{Cl}^{-}\right]+370.8\left[\mathrm{SO}_{4}{ }^{2-}\right]+748.9\left[\mathrm{NO}_{3}{ }^{-}\right]$

weathering $=313.4\left[\mathrm{HCO}_{3}{ }^{-}\right]+421.0\left[\mathrm{SiO}_{2}\right]$

- the $w \%$-agriculture (factor 2), with agriculture $=63.4\left[\mathrm{SO}_{4}{ }^{2-}\right]+591.6\left[\mathrm{NO}_{3}{ }^{-}\right]$ dom. effluents/atm. input $=377.0\left[\mathrm{Cl}^{-}\right]$.

The water samples were assembled into three groups: 1 , weathering ( $w \%$ pollution $<50 \%$ ); 2 , domestic effluents ( $w \%$-pollution $>50 \%$ and $w \%$-agriculture $<50 \%$ ); 3 , farmland fertilizers ( $w \%$-pollution $>50 \%$ and $w \%$-agriculture $>50 \%$ ). 
Table 1. Results of the CA Procedure

\begin{tabular}{|c|c|c|c|c|}
\hline & $F_{1}$ & $F_{2}$ & $F_{3}$ & $F_{4}$ \\
\hline \multicolumn{5}{|l|}{ Distribution of variance } \\
\hline Eigenvalue $(\times 1000)$ & 190.5 & 74.8 & 44.9 & 34.6 \\
\hline$\% F_{i}$ & 55.3 & 21.7 & 13.0 & 10.0 \\
\hline Cum- $\% F$ & 55.3 & 77.0 & 90.0 & 100.0 \\
\hline \multicolumn{5}{|c|}{ Correspondence factor loadings $(\times 1000)$} \\
\hline $\mathrm{HCO}_{3}^{-}$ & 313.4 & 92.0 & -202.6 & 164.6 \\
\hline $\mathrm{Cl}^{-}$ & -443.0 & 377.0 & 178.3 & 14.6 \\
\hline $\mathrm{SO}_{4}{ }^{2-}$ & -370.8 & -63.4 & -346.5 & -394.1 \\
\hline $\mathrm{NO}_{3}^{-}$ & -748.9 & -591.6 & 35.7 & 235.5 \\
\hline $\mathrm{SiO}_{2}$ & 421.0 & -160.3 & 210.3 & -114.7 \\
\hline \multicolumn{5}{|c|}{ MLR model relating hydrochemical parameters with factors } \\
\hline & $B_{1}$ & $B_{2}$ & $B_{3}$ & $R^{2}(\%)$ \\
\hline$w \%$-Pollution & 51.4 & 1.4 & 0.6 & 99.1 \\
\hline$w \%$-Agriculture & 22.1 & 68.5 & 12.0 & 77.9 \\
\hline
\end{tabular}

Source. Adapted from Pacheco (1998b). Symbols: $\% F_{i}$, percentage of data variation explained by $F_{i}$; Cum- $\% F$, cumulative $\% F_{i} ; B_{i}$, standardized regression coefficient of factor $F_{i} ; R^{2}$, adjusted coefficient of multiple determination; $w \%$-pollution and $w \%$-agriculture, hydrochemical parameters calculated by Equations (2) and (3).

The results of this classification are listed in the Appendix under the heading CA/DA-prior.

The relation between hydrochemical parameters and factors was set on the basis of MLR and the results are summarized in the last two rows of Table 1. The MLR model for $w \%$-pollution holds a $R^{2}=99.1 \%$ indicating a tight regression between this parameter and $F_{1}$, but no similar link exists between the $w \%$-agriculture parameter and $F_{2}$ (in the latter case $R^{2}=77.9 \%$ ). In view of such uncertainty, we used DA to optimize the location of the samples with respect to the three pre-defined groups. The results are in column CA/DA-post of the Appendix and reveal that 15 samples $(9.4 \%)$ were reclassified into a different group. Using the optimized memberships of the samples and gridding as explained above, we drew Figure 3 that illustrates the areas of influence of each CA group.

\section{Results of CIA/DA}

The results from Ward's method are described in detail in the Appendix (column ClA/DA-prior). These groupings were used as a training set for DA which provided the post assignments listed in column ClA/DA-post.

The confusion matrix comparing the $\mathrm{CA} / \mathrm{DA}$ and $\mathrm{ClA} / \mathrm{DA}$ results is shown in Table 2. There is little doubt that group A is equivalent to group 1 (the weathering 


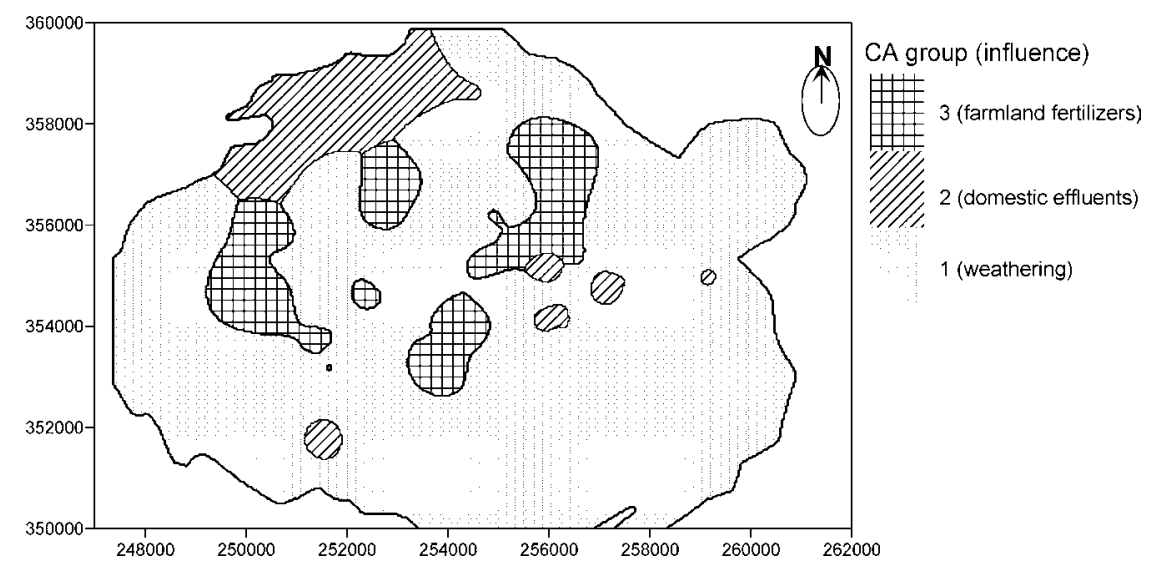

Figure 3. Spatial distribution of group memberships determined by the results of CA optimized by DA.

group), but the associations between groups $2 / 3$ and $\mathrm{B} / \mathrm{C}$ are less evident. The medians of $w \%$-pollution and $w \%$-agriculture suggest that group $\mathrm{B}$ and group 3 are influenced by farmland fertilizers, whereas group $\mathrm{C}$, although falling in the field of weathering, has a median $w \%$-agriculture compatible with group 2 (influence by domestic effluents). Based on these associations we drew Figure 4 to show the areas of influence of each $\mathrm{ClA} / \mathrm{DA}$ group.

\section{Results of Node Analysis}

Employing NA we combined Figures 3 and 4 obtaining Figure 5. The grids used were rectangles with $l=400$ columns and $h=300$ rows. The recasting of grid nodes was performed as follows: (1) when nodes in the one-way RC grids

Table 2. Confusion Matrix Comparing the Results Obtained by CA/DA (1, 2 and 3) and ClA/DA (A, B and C) Groupings

\begin{tabular}{lrrrrcc}
\hline & $\mathrm{A}$ & $\mathrm{B}$ & $\mathrm{C}$ & Total & $w \%$-Pollution & $w \%$-Agriculture \\
\hline 1 & 88 & 0 & 36 & 124 & 29.0 & 35.6 \\
2 & 1 & 7 & 5 & 13 & 74.2 & 36.1 \\
3 & 12 & 5 & 6 & 23 & 63.3 & 64.4 \\
Total & 101 & 12 & 47 & 160 & & \\
$w \%$-Pollution & 30.5 & 78.4 & 40.8 & & & \\
$w \%$-Agriculture & 37.5 & 56.7 & 38.7 & & & \\
\hline
\end{tabular}

Note. Associated medians of the $w \%$-pollution and $w \%$-agriculture parameters as determined by Equations (2) and (3). 


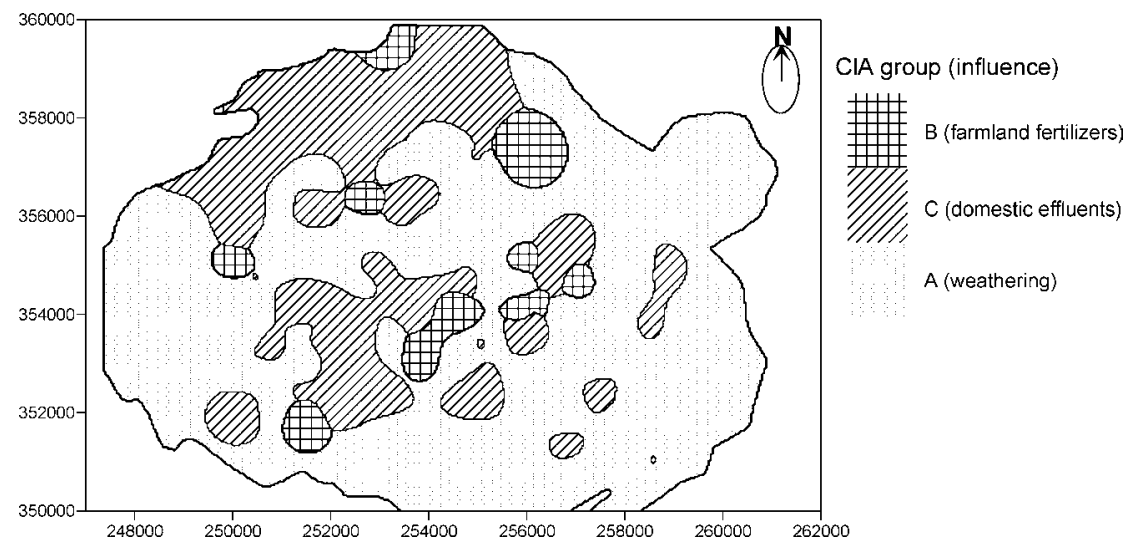

Figure 4. Spatial distribution of group memberships determined by the results of ClA optimized by DA.

(Figs. 3 and 4) had the same value (1, 2 or 3 depending on whether their group memberships were $1 / \mathrm{A}, 2 / \mathrm{C}$ or $3 / \mathrm{B}$ ) they preserved this value in the two-way RC (Fig. 5); (2) when group memberships in the original grids differ but one had the a value of 3 (fertilizer's influence) they were recast as 4 (mixing between fertilizer and other influences) in the combined grid; (3) in all other cases the two-way RC nodes were recast as 0 (mixing between weathering and domestic effluents).

The areas with weathering-dominated water chemistries occupy most of the studied region, working out as areas of background hydrochemistry. The dominance of effluents is restricted to the region of Alcaria, where the Meimoa river intersects the Zêzere river and some streamlets intersect the Meimoa river

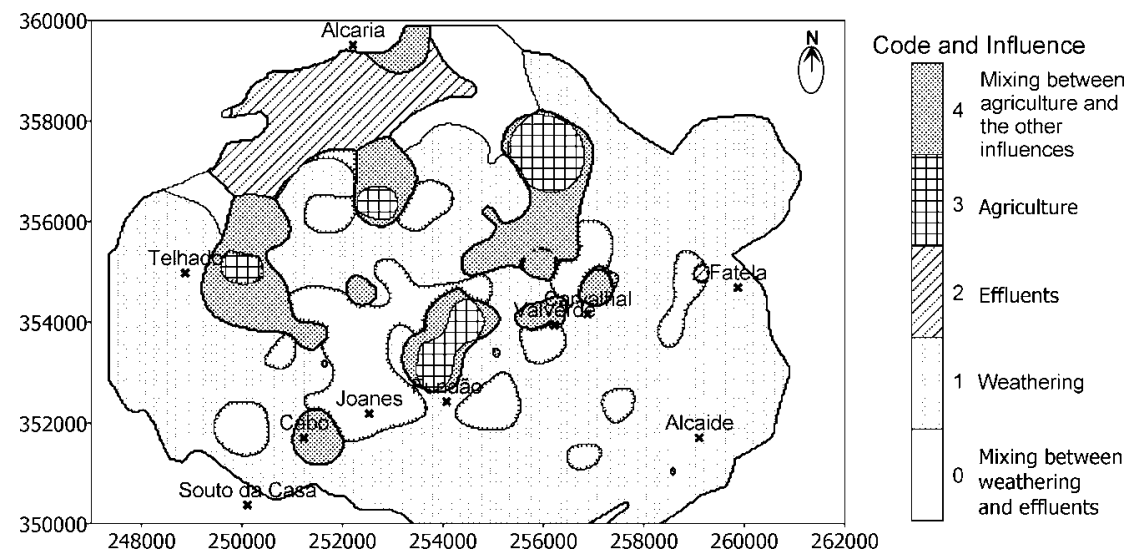

Figure 5. Results of node analysis. 
(Fig. 2). However, a substantial surface area upstream from the Meimoa river is occupied by regions where effluents blur the background compositions generated by weathering (white areas). Apparently the direct discharge of domestic effluents into streams and streamlets produces regions of mixing that are converted by some concentration process into a region of effluent-dominated water chemistries south of Alcaria. In all cases the areas with fertilizer-dominated water chemistries are spots surrounded by a zone of fluid mixing.

\section{TWO-WAY RC AND THE ASSESSMENT OF HYDRODYNAMIC DISPERSION}

Hydrodynamic dispersion of a solute in groundwater occurs as a consequence of two different processes: mechanical dispersion and molecular diffusion. Mechanical dispersion is a process of fluid mixing that causes a zone of mixing to develop between a fluid of one composition that is adjacent to or is being displaced by a fluid of another composition. It occurs as a result of variations around some mean velocity of flow. These variations are caused by the porous medium heterogeneities at the microscopic, macroscopic and megascopic scales (e.g. variations in the hydraulic conductivity, grain's sorting, etc.). Molecular diffusion originates because of mixing caused by random molecular motions due to the thermal kinetic energy of the solute, i.e. it is a chemical rather than a physical (advective) process.

The results of two-way $\mathrm{RC}$ regarding the areas with fertilizer-dominated water chemistries (cross-hatched areas in Fig. 5) suggest that some dispersion of the fertilizers took place after their application on farmland, because these areas are completely surrounded by a region of mixing (dark grey areas). It seems like the fertilizers applied in Spring (starting in early March) to feed the Summer crops have moved downstream and formed pulse-like contaminant plumes, which in turn have grown large and get diluted in their outer rims due to hydrodynamic dispersion. The sampling made in June-July worked out as a snapshot of the plumes when they were 4 months old. The purpose now is to quantify the hydrodynamic dispersion, but first some mathematical background must be introduced.

\section{Mathematical Background on Hydrodynamic Dispersion}

When a solute is subject to effective leaching, as usually happens in soils and saprolites derived from granites, mechanical dispersion grows several orders of magnitude higher than molecular diffusion, swamping the effects of this latter phenomenon (Pfannkuch, 1962). In such cases hydrodynamic dispersion is represented mathematically by:

$$
D=v \times \alpha
$$


with

$$
v=\frac{K \times \operatorname{grad}(h)}{m_{\mathrm{e}}}
$$

where $D$ is the coefficient of hydrodynamic dispersion, $v$ the solute's velocity in the mean direction of flow and $\alpha$ a characteristic property of mechanical dispersivity; $K, \operatorname{grad}(h)$ and $m_{\mathrm{e}}$ are the hydraulic conductivity, hydraulic gradient and effective porosity. Hydrodynamic dispersion may be expressed by longitudinal (in the direction of flow) and transverse (at right angles) spreadings where the $D$ and $\alpha$ coefficients are represented with $L$ or $T$ subscripts (e.g. $D_{\mathrm{L}}$ or $\alpha_{\mathrm{T}}$ ).

Assessment of the dispersion coefficients is essential for models of contaminant transport to work. Among the models in use, we focus on those dealing with localized and non-continuous sources of contamination, like the periodic application of fertilizers to farmland. According to these pulse-type models, the movement of a contaminant (e.g. sulphate) across the porous medium generates a growing plume due to hydrodynamic dispersion. One important feature of the concentration distribution inside the plume is that after a short period of time it becomes normal. The mean of the distribution describes the position of the plume and the variance $\left(\sigma_{\mathrm{L}}^{2}\right.$ or $\sigma_{\mathrm{T}}^{2}$ of the longitudinal and transverse dispersions. The corresponding coefficients of hydrodynamic dispersion are given by (Domenico and Schwartz, 1990):

$$
D_{\mathrm{L}}=\frac{\sigma_{\mathrm{L}}^{2}}{2 t} \quad D_{\mathrm{T}}=\frac{\sigma_{\mathrm{T}}^{2}}{2 t}
$$

where $t$ is the time passed since the contaminant entered the system.

\section{The Analog Pulse-Type Model Based on Group Memberships}

Application of pulse-type models [estimation of $\sigma$ in Eq. (7)] requires that concentration distributions within contaminant plumes are well defined. This occurs when plumes are composed of a solute introduced artificially in the system (a tracer). In these cases solute concentrations inside and outside the plumes usually contrast. Contrarily, when plumes result from dissolution of fertilizers in ground waters also affected by weathering and domestic effluents (present case), the overlapping of several and sometimes similar sources of solutes masks the boundaries between plumes and the natural environment, making it difficult to quantify the mass transport parameters. In these cases we would need first to define a sharp boundary around the plumes and then use a proxy to describe the concentration distributions inside them. We believe that this is performed adequately by the two-way RC approach: the boundary of a plume is defined by the outer limit of a dark grey area enclosing a cross-hatched area (Fig. 5). The concentrations are represented by the membership probabilities of groups linked 
to the agriculture influence $(1 / 2 \times($ group $3+$ group B $))$, listed in the Appendix under the heading Prob-3/B.

In total there are four contaminant plumes in Figure 5, which were termed Telhado, South of Alcaria, Fundão and North of Valverde in reference to the closest town. From data in column Prob-3/B of the Appendix, we drew contours of membership probability inside the plumes and shaded the space between those corresponding to the means and means minus standard deviations (Fig. 6a-d). The thicknesses of the shaded areas in the directions of elongation and at right angles are measures of $\sigma_{\mathrm{L}}$ and $\sigma_{T}$, respectively.

\section{Hydrology of the Fundão Soils}

Apart from the estimation of $\sigma$, quantification of dispersivities [Eq. (6a)] requires that some hydrologic information is available on the studied porous media; namely, mean velocities of flow, which in turn are dependent on hydraulic

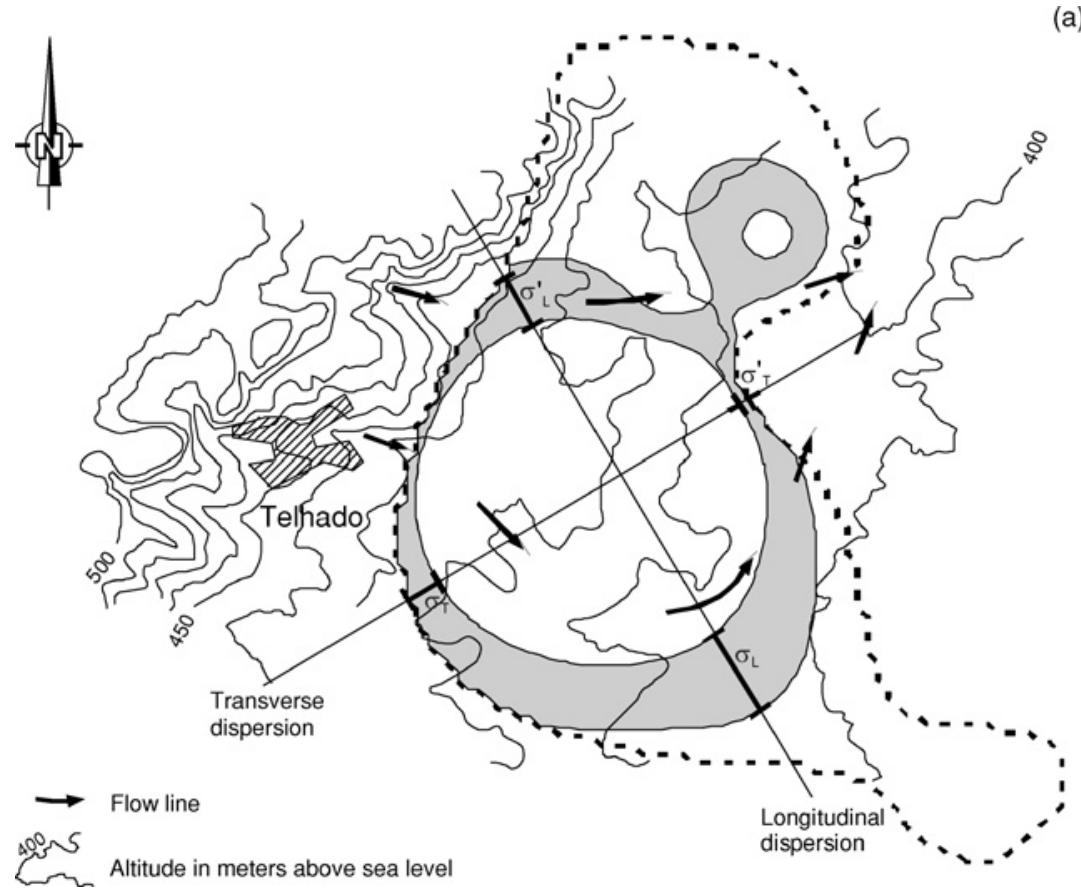

Figure 6. Topography around the contaminant plumes: (a) Telhado, (b) South of Alcaria, (c) Fundão, and (d) North of Valverde. The plumes are represented by dashed thick polygons. The shaded areas describe the regions inside the plumes where group-3/B membership probabilities range from the mean to the mean minus standard deviation. The thickness of the shaded areas is a measure of $\sigma$ [Eq. (7)]. The samples' group-3/B memberships are listed in the Appendix. 


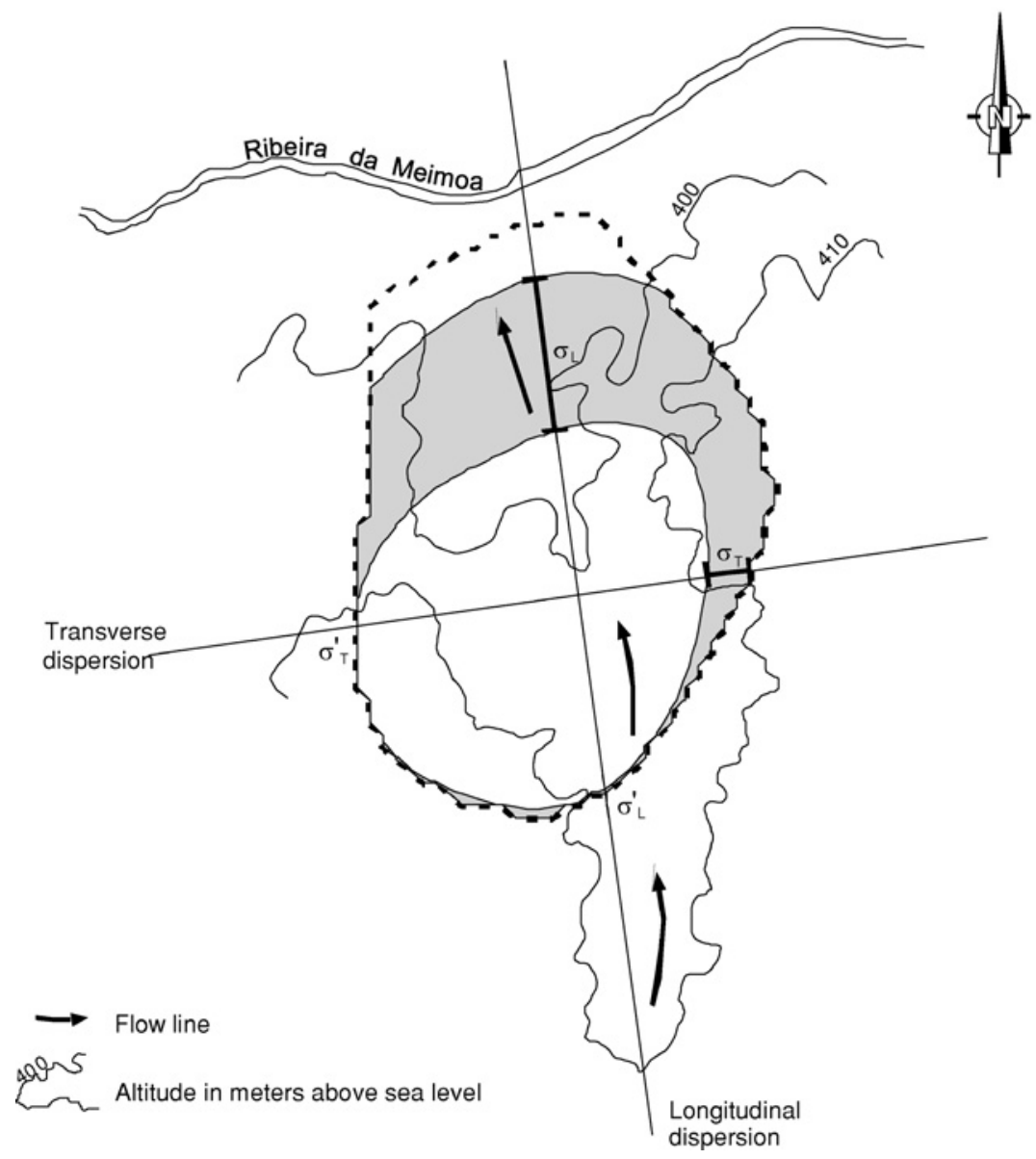

Figure 6. Continued.

gradients, hydraulic conductivities and effective porosities [Eq. (6b)]. Hydraulic gradients may be approached by topographic gradients. The other necessary hydrologic information is compiled in the next paragraph.

Costa and others (1971) collected a set of 37 soil samples from the region of Fundão and analysed them for grain size (Table 3). Hydraulic conductivities were estimated from the grain size distributions using the formula of Krumbein and Monk (1943):

$$
K=760 d^{2} \mathrm{e}^{-1.31 \delta}
$$




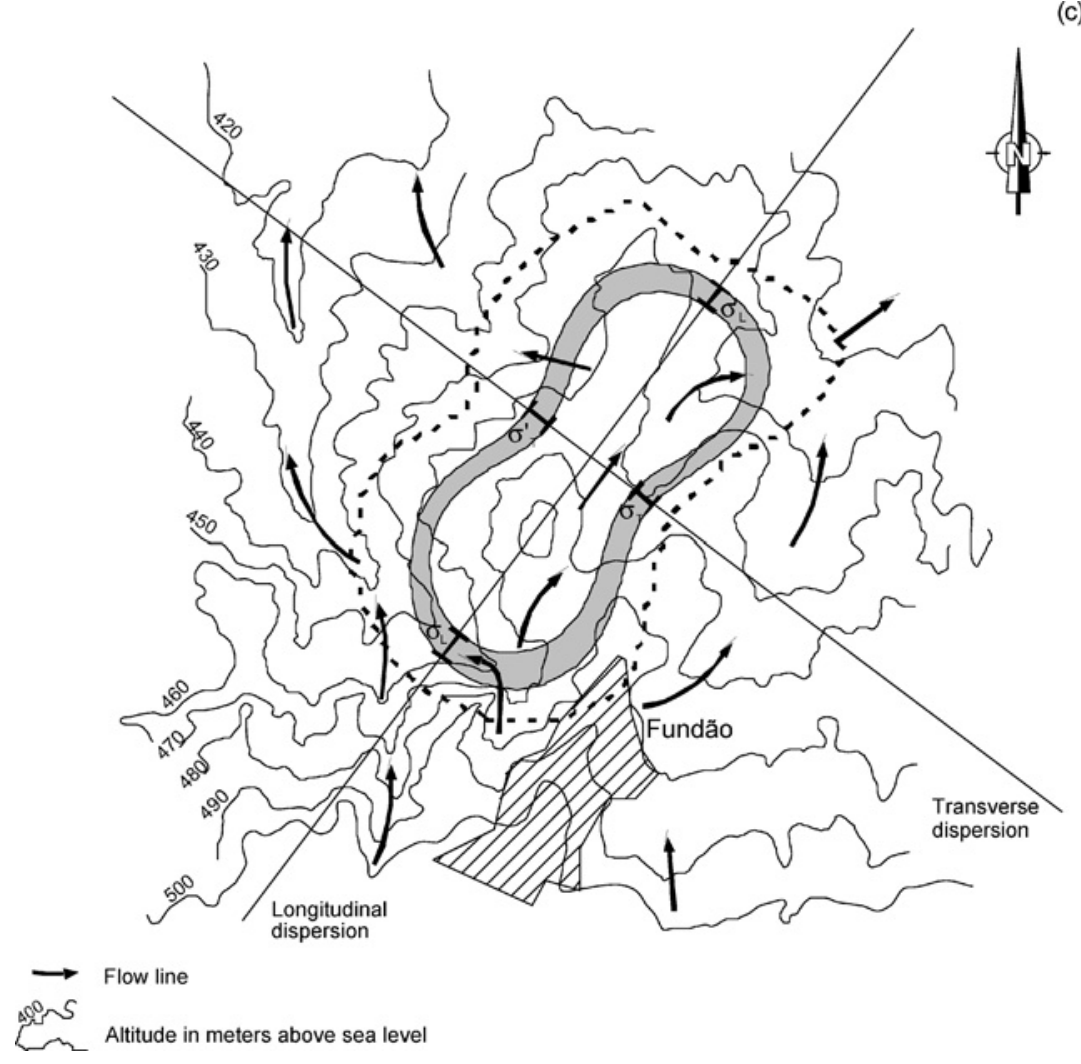

(c)

Figure 6. Continued.

where $K$ is the hydraulic conductivity given in darcys (conversion to $\mathrm{m} / \mathrm{s}$ implies a division by 1,04,000), $d$ the geometric mean diameter (in millimeters) and $\delta$ the $\log$ standard deviation of the grain size distribution. The $\log (K)$ values are listed in the last column of Table 3 and their spatial distribution is shown in Figure 7. Effective porosities have been estimated by an analytical method cited in Custodio and Llamas (1983):

$$
m_{\mathrm{e}}=m_{\mathrm{t}}-\Psi \quad \Psi=0.03 \times \text { sand }+0.35 \times \text { loam }+1.65 \times \text { clay }
$$

where $m_{\mathrm{t}}$ and $m_{\mathrm{e}}$ are the total and effective porosities of the soil and $\psi$ is its specific retention; sand, loam and clay are the proportions of the sand, loam and clay fractions in the sample (Table 3). For $m_{\mathrm{t}}$ we assumed a value of 50\%, which is common for soils derived from granites. The $m_{\mathrm{e}}$ values obtained by Equation (9) were interpolated across the Fundão area and some contours were drawn (Fig. 8). 


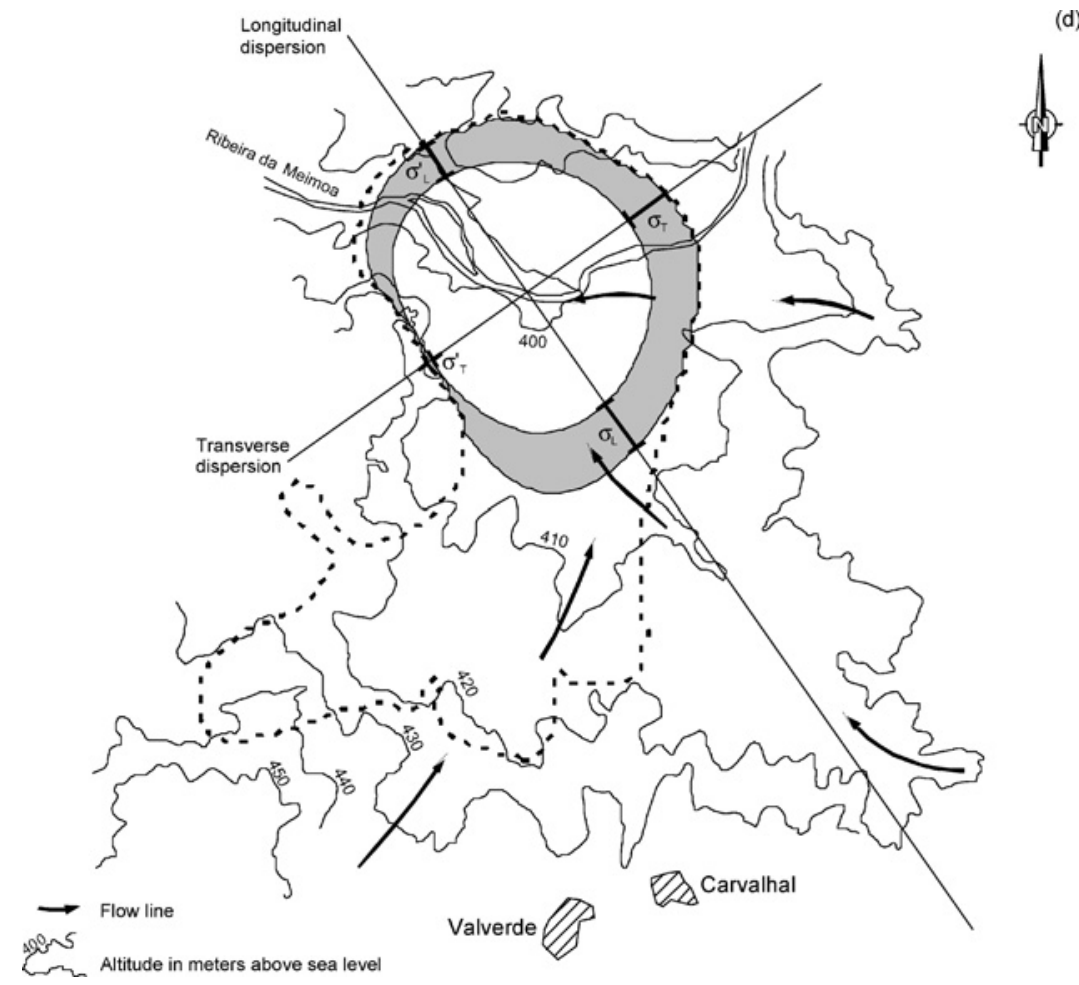

Figure 6. Continued.

\section{Dispersivities of the Fundão Soils}

From Figure $6 \mathrm{a}-\mathrm{d}$ we estimated the plumes' $\sigma_{\mathrm{L}}^{2}$ and $\sigma_{\mathrm{T}}^{2}$ and then calculated the plumes' hydrodynamic dispersions using Equation (7), assuming that $t=4$ months (the age of the plumes). From Figures 7 and 8 we averaged the plumes' hydraulic conductivities and effective porosities. Using this information in combination with hydraulic gradients deduced from Figure $6 \mathrm{a}-\mathrm{d}$, we determined flow velocities [Eq. (6b)] that when combined with the previously calculated hydrodynamic dispersions gave estimates for the longitudinal and transverse dispersivities [Eq. (6a)]. All results are shown in Table 4.

The values of $\alpha_{\mathrm{L}}$ range from 0.7 to $16.8 \mathrm{~m}$. They are acceptable because in this study we are dealing with the assessment of dispersivities at the macroscopic scale. As expected, the $\alpha_{\mathrm{T}}$ values are always smaller than the $\alpha_{\mathrm{L}}$ values. The ratios $\alpha_{\mathrm{L}} / \alpha_{\mathrm{T}}$ are within the interval $[1.2,12.6] \mathrm{m}$, a range that has already been found by other authors. The use of a single $t$ is obviously a source of uncertainty because application of fertilizers is not restricted to a single day. The value of 4 months is 
Table 3. Grain Size Distributions, Hydraulic Conductivities and Effective Porosities of 37 Soil Samples From the Fundão Region

\begin{tabular}{|c|c|c|c|c|c|c|c|c|c|}
\hline \multirow{2}{*}{\multicolumn{3}{|c|}{ Identification }} & \multicolumn{5}{|c|}{ Grain size distribution (ranges in $\mathrm{mm}$, values in wt $\%$ ) } & \multirow{2}{*}{\multicolumn{2}{|c|}{$\begin{array}{l}\text { Physical } \\
\text { parameters }\end{array}$}} \\
\hline & & & \multicolumn{2}{|c|}{ Sand } & \multicolumn{2}{|c|}{ Loam } & \multirow{2}{*}{$\frac{\text { Clay }}{<0.002}$} & & \\
\hline $\mathrm{nr}$ & $M(\mathrm{~m})$ & $P(\mathrm{~m})$ & $>2$ & $2-0.05$ & $0.05-0.02$ & $0.02-0.002$ & & $\log (K)$ & $m_{e}$ \\
\hline 1 & $2,51,980$ & $3,55,554$ & 24.6 & 51.0 & 6.2 & 10.4 & 5.7 & -2.08 & 0.32 \\
\hline 2 & $2,53,424$ & $3,52,614$ & 5.9 & 36.9 & 14.5 & 24.1 & 18.4 & -2.52 & 0.05 \\
\hline 3 & $2,53,144$ & $3,52,897$ & 11.4 & 63.9 & 6.3 & 9.6 & 3.4 & -2.17 & 0.36 \\
\hline 4 & $2,53,271$ & $3,54,764$ & 25.1 & 52.9 & 4.7 & 12.1 & 5.0 & -2.06 & 0.33 \\
\hline 5 & $2,51,206$ & $3,51,810$ & 18.5 & 67.1 & 5.7 & 6.4 & 1.5 & -2.06 & 0.41 \\
\hline 6 & $2,54,266$ & $3,53,084$ & 28.4 & 51.4 & 6.2 & 10.0 & 2.2 & -2.03 & 0.38 \\
\hline 7 & $2,50,099$ & $3,54,408$ & 18.2 & 65.3 & 3.8 & 8.0 & 3.2 & -2.07 & 0.38 \\
\hline 8 & $2,49,208$ & $3,51,786$ & 10.0 & 71.7 & 5.3 & 7.8 & 4.3 & -2.14 & 0.36 \\
\hline 9 & $2,54,393$ & $3,54,426$ & 9.2 & 72.1 & 4.9 & 11.4 & 1.5 & -2.15 & 0.39 \\
\hline 10 & $2,54,490$ & $3,53,072$ & 29.1 & 49.5 & 5.0 & 10.3 & 4.2 & -2.04 & 0.35 \\
\hline 11 & $2,54,691$ & $3,53,406$ & 8.9 & 71.7 & 5.0 & 11.2 & 1.3 & -2.15 & 0.40 \\
\hline 12 & $2,51,966$ & $3,56,192$ & 18.1 & 65.7 & 4.3 & 7.6 & 3.4 & -2.07 & 0.38 \\
\hline 13 & $2,48,191$ & $3,52,669$ & 12.5 & 77.8 & 1.8 & 5.2 & 2.5 & -2.07 & 0.41 \\
\hline 14 & $2,53,926$ & $3,55,384$ & 2.2 & 80.6 & 6.0 & 8.3 & 1.7 & -2.19 & 0.40 \\
\hline 15 & $2,55,549$ & $3,53,221$ & 3.0 & 65.2 & 10.0 & 15.0 & 4.8 & -2.30 & 0.31 \\
\hline 16 & $2,53,636$ & $3,56,950$ & 18.8 & 69.6 & 3.8 & 4.2 & 2.8 & -2.04 & 0.40 \\
\hline 17 & $2,55,132$ & $3,56,889$ & 18.5 & 66.8 & 3.5 & 7.4 & 3.2 & -2.06 & 0.38 \\
\hline 18 & $2,57,768$ & $3,54,582$ & 1.6 & 80.3 & 5.0 & 10.5 & 2.2 & -2.20 & 0.38 \\
\hline 19 & $2,57,059$ & $3,55,671$ & 2.3 & 81.0 & 1.3 & 9.8 & 5.3 & -2.19 & 0.35 \\
\hline 20 & $2,50,432$ & $3,55,914$ & 7.2 & 67.8 & 11.5 & 4.8 & 4.6 & -2.21 & 0.34 \\
\hline 21 & $2,52,911$ & $3,51,265$ & 3.2 & 82.2 & 4.7 & 7.8 & 1.1 & -2.16 & 0.41 \\
\hline 22 & $2,51,028$ & $3,50,888$ & 5.2 & 50.9 & 10.4 & 20.3 & 11.7 & -2.39 & 0.18 \\
\hline 23 & $2,56,420$ & $3,55,492$ & 3.0 & 65.9 & 7.1 & 12.1 & 10.2 & -2.29 & 0.24 \\
\hline 24 & $2,57,132$ & $3,56,479$ & 1.3 & 76.8 & 5.9 & 10.9 & 4.5 & -2.23 & 0.34 \\
\hline 25 & $2,54,075$ & $3,58,061$ & 5.2 & 74.8 & 2.4 & 10.3 & 6.8 & -2.19 & 0.32 \\
\hline 26 & $2,59,283$ & $3,53,968$ & 2.1 & 68.7 & 4.3 & 12.7 & 11.5 & -2.28 & 0.23 \\
\hline 27 & $2,57,763$ & $3,53,661$ & 21.4 & 63.4 & 3.0 & 6.8 & 4.4 & -2.05 & 0.37 \\
\hline 28 & $2,55,701$ & $3,52,352$ & 1.6 & 66.3 & 7.0 & 16.4 & 8.0 & -2.31 & 0.26 \\
\hline 29 & $2,57,728$ & $3,52,449$ & 3.5 & 65.1 & 7.4 & 13.2 & 7.6 & -2.29 & 0.27 \\
\hline 30 & $2,54,891$ & $3,59,752$ & 17.0 & 53.1 & 9.8 & 14.3 & 4.8 & -2.17 & 0.31 \\
\hline 31 & $2,60,713$ & $3,54,768$ & 10.8 & 30.2 & 9.8 & 29.9 & 14.9 & -2.48 & 0.08 \\
\hline 32 & $2,48,056$ & $3,55,286$ & 13.2 & 61.0 & 5.8 & 12.0 & 7.0 & -2.17 & 0.30 \\
\hline 33 & $2,50,026$ & $3,52,255$ & 3.9 & 73.7 & 3.8 & 11.5 & 6.1 & -2.21 & 0.32 \\
\hline 34 & $2,50,539$ & $3,53,009$ & 7.8 & 69.7 & 5.4 & 10.9 & 5.6 & -2.18 & 0.33 \\
\hline 35 & $2,54,066$ & $3,58,209$ & 6.0 & 71.7 & 6.6 & 10.6 & 4.4 & -2.20 & 0.34 \\
\hline 36 & $2,57,749$ & $3,59,193$ & 24.6 & 51.0 & 6.2 & 10.4 & 5.7 & -2.08 & 0.32 \\
\hline 37 & $2,59,381$ & $3,56,181$ & 4.9 & 68.0 & 7.1 & 12.6 & 6.4 & -2.24 & 0.30 \\
\hline
\end{tabular}

Source. Original data (grain sizes) compiled from Costa and others (1971). Hydraulic conductivities estimated by the method of Krumbein and Monk (1943), and effective porosities by a method cited in Custodio and Llamas (1983) assuming an average total porosity of 50\%. Symbols: nr, number of the soil sample; $M$ and $P$, Hayford-Gauss coordinates of the soil samples (locations in Figs. 7 and 8); $K$, hydraulic conductivity; $m_{\mathrm{e}}$, effective porosity. 


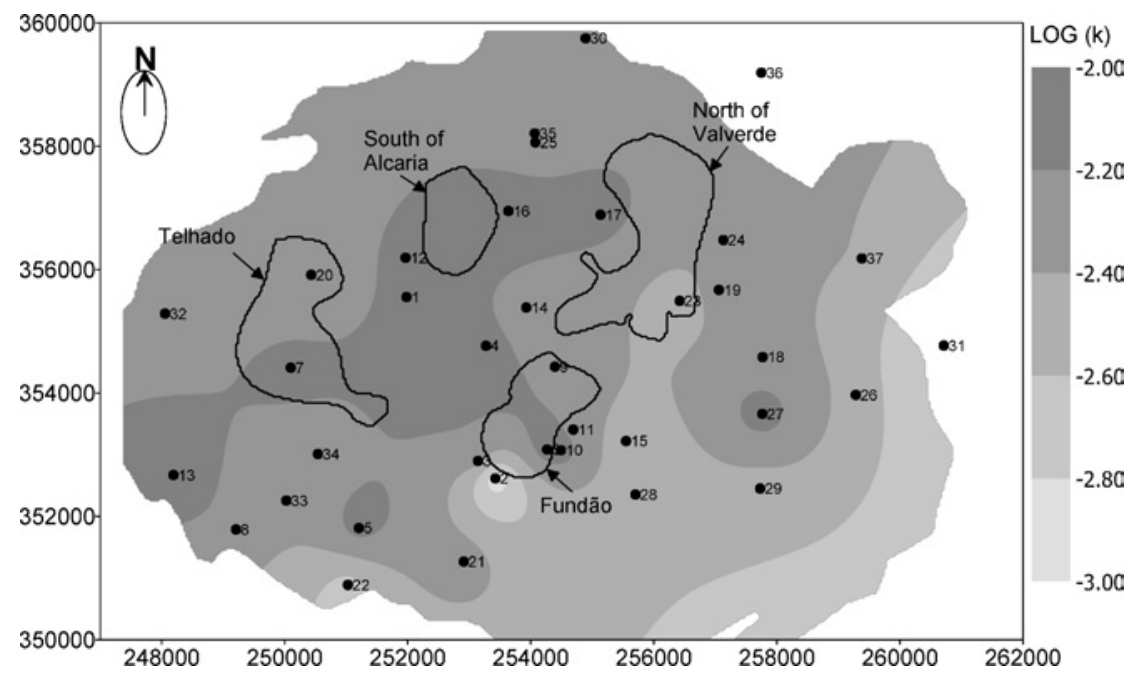

Figure 7. Spatial distribution of the Fundão soils' hydraulic conductivities. The numbers near the dots are sample numbers as listed in Table 3. The labelled polygons are the four contaminant plumes.

the largest gap between the actions of fertilizing and water sampling. A value for the smallest gap would be 2 months or so, for crops seeded in late April. Adoption of $t=2$ months would raise the $\alpha_{\mathrm{L}}$ and $\alpha_{\mathrm{T}}$ dispersivities by a factor of 2 , but their ranges would be kept under acceptable values.

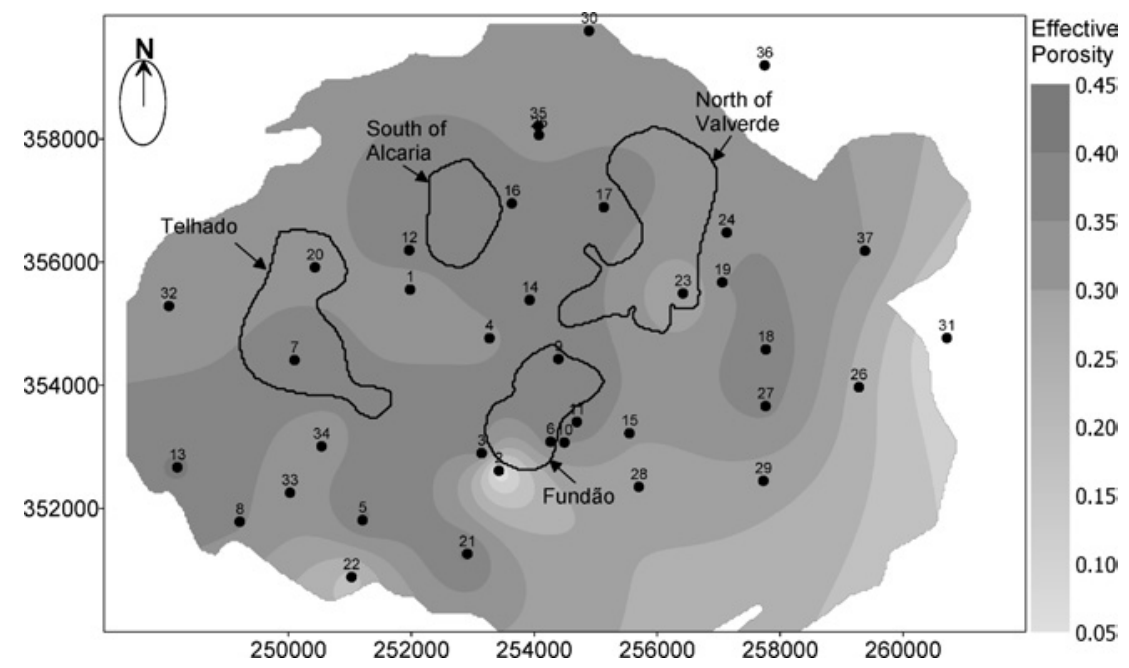

Figure 8. Spatial distribution of the Fundão soils' effective porosities. The numbers near the dots are sample numbers as listed in Table 3 . The labelled polygons are the four contaminant plumes. 
Table 4. Results of the Procedures Used to Estimate the Longitudinal and Transverse Dispersivities of the Fundão Soils

\begin{tabular}{|c|c|c|c|c|c|}
\hline \multirow[b]{2}{*}{ Direction } & \multirow[b]{2}{*}{ Parameter } & \multicolumn{4}{|c|}{ Contaminant Plume } \\
\hline & & A (Telhado) & $\begin{array}{l}\text { B (South } \\
\text { of Alcaria) }\end{array}$ & C (Fundão) & $\begin{array}{c}\mathrm{D} \text { (North } \\
\text { of Valverde) }\end{array}$ \\
\hline & $\begin{array}{l}\text { Mean group-3/B } \\
\text { probability }\end{array}$ & 0.4 & 0.4 & 0.6 & 0.5 \\
\hline & $\begin{array}{l}\text { Associated standard } \\
\text { deviation }\end{array}$ & 0.1 & 0.2 & 0.1 & 0.1 \\
\hline & $m_{e}$ & 0.35 & 0.38 & 0.35 & 0.33 \\
\hline & $\log (K)$ & -2.13 & -2.08 & -2.15 & -2.18 \\
\hline & $\operatorname{grad}(h)$ & 0.041 & 0.0068 & 0.0382 & 0.0094 \\
\hline & $v \times 10^{-4}(\mathrm{~m} / \mathrm{s})$ & 8.5 & 1.5 & 7.7 & 1.9 \\
\hline \multirow[t]{4}{*}{ Longitudinal } & $\sigma_{L}(\mathrm{~m})$ & 328.75 & 445.47 & 117.85 & 276.54 \\
\hline & $\sigma_{L}^{\prime}(\mathrm{m})$ & 200.18 & 13.21 & 92.8 & 202.47 \\
\hline & $D_{L}\left(\mathrm{~cm}^{2} / \mathrm{s}\right)$ & 33.7 & 25.4 & 5.3 & 27.7 \\
\hline & $\alpha_{L}(\mathrm{~m})$ & 3.9 & 16.8 & 0.7 & 14.8 \\
\hline \multirow[t]{4}{*}{ Transverse } & $\sigma_{T}(\mathrm{~m})$ & 129.16 & 124.3 & 98.76 & 237.58 \\
\hline & $\sigma_{T}^{\prime}(\mathrm{m})$ & 29.46 & 5 & 94.84 & 20.74 \\
\hline & $D_{T}\left(\mathrm{~cm}^{2} / \mathrm{s}\right)$ & 3.0 & 2.0 & 4.5 & 8.0 \\
\hline & $\alpha_{T}(\mathrm{~m})$ & 0.4 & 1.3 & 0.6 & 4.3 \\
\hline Cross & $D_{L} / D_{T}$ & 11.1 & 12.6 & 1.2 & 3.4 \\
\hline
\end{tabular}

Note. $m_{\mathrm{e}}$, effective porosity; $K$, hydraulic conductivity; $\operatorname{grad}(h)$, hydraulic gradient; $v$, mean velocity of flow; $\sigma_{\mathrm{L}}, \sigma_{\mathrm{L}}^{\prime}, \sigma_{\mathrm{T}}, \sigma_{\mathrm{T}}^{\prime}$, standard deviations of group-3/B membership probabilities (spatial representation); $D_{\mathrm{L}}$ and $D_{\mathrm{T}}$, coefficients of hydrodynamic dispersion; $\alpha_{\mathrm{L}}$ and $\alpha_{\mathrm{T}}$, mechanical dispersivities.

\section{CONCLUSIONS}

Hydrodynamic dispersion at the macroscopic and larger scales is an interesting and still unsolved research topic. In the previous sections of this paper we showed how the shapes and concentration distributions of contaminant plumes can be assessed by the application of our two-way RC and, notwithstanding limitations in accounting for the age of the plumes, demonstrated that quantification of mechanical dispersivities by this method leads to reliable results not only at the level of absolute values of the longitudinal and transverse components but also at the level of the ratios between them.

\section{REFERENCES}

Costa, C. V., Pereira, L. G., Portugal Ferreira, M., and Santos Oliveira, J. M., 1971, Distribuição de oligoelementes nas rochas e solos da região do Fundão: Memórias e Notícias (Publicações do Museu e Laboratório Mineralógico e Geológico da Universidade de Coimbra), v. 71, p. 1-37. 
Custodio, E., and Llamas, M. R., 1983, Hidrología subterránea: Ediciones Omega, Barcelona, Spain, Vol. 1, 1157 p.

Domenico, P. A., and Schwartz, F. W., 1990, Physical and chemical hydrogeology: Wiley, New York, $824 \mathrm{p}$.

Harff, J., and Davis, J. C., 1990, Regionalization in geology by multivariate classification: Math. Geol., v. 22 , no. 5 , p. $577-588$.

Jackson, J. E., 1991, A user's guide to principal components: Wiley, New York, 569 p.

Jobson, J. D., 1992, Applied multivariate data analysis, Vol. 1. Regression and experimental design: Springer-Verlag, New York, $621 \mathrm{p}$.

Kaufman, L., and Rousseeuw, P. J., 1990, Finding groups in data: Wiley, New York, 342 p.

Krumbein, W. C., and Monk, G. D., 1943, Permeability as a function of the size parameters of unconsolidated sand: Trans. Am. Inst. Min. Met. Eng., v. 151, p. 153-163.

Olea, R. A., 1999, Geostatistics for engineers and earth scientists: Kluwer Academic Publishers, chapter 14.

Pacheco, F. A. L., 1998a, Finding the number of natural clusters in groundwater data sets using the concept of equivalence class: Comp. Geosci., v. 24, no. 1, p. 7-15.

Pacheco, F. A. L., 1998b, Application of correspondence analysis in the assessment of groundwater chemistry: Math. Geol., v. 30, no. 2, p. 129-161.

Pacheco, F. A. L., and Van der Weijden, C. H., 1996, Contributions of water-rock interactions to the composition of groundwater in areas with sizeable anthropogenic input: A case study of the waters of the Fundão area, central Portugal: Water Resour. Res., v. 32, no. 12, p. 3553-3570.

Pacheco, F. A. L., Sousa Oliveira, A., Van der Weijden, A. J., and Van der Weijden, C. H., 1999, Weathering, biomass production and groundwater chemistry in an area of dominant anthropogenic influence, the Chaves-Vila pouca de Aguiar region, north of Portugal: Water, Air Soil Pollut., v. 115 , no. $1 / 4$, p. $481-512$.

Pfannkuch, H. O., 1962, Contribution à l'étude des deplacement des fluides miscible das un milieu poreux: Rev. Inst. Fr. Petrol., v. 18, no. 2, p. 215-270.

Van der Weijden, C. H., Oosterom, M. G., Bril, J., Walen, C. G., Vriend, S. P., and Zuurdeeg, B. W., 1983, Geochemical controls of transport and deposition of uranium from solution. Case study: Fundão, Portugal: Technical Report, EC contract 007.79.3 EXU NL, Department of Geochemistry, Institute of Earth Sciences, Utrecht University, 67 p.

Ward, J. H., 1963, Hierarchical grouping to optimize an objective function: J. Am. Stat. Assoc., v. 58, p. $238-244$.

\section{APPENDIX}

Location of the sampling sites (Hayford-Gauss $M$ and $P$ coordinates). Concentrations of major anions and silica in the 160 spring water samples collected by Van der Weijden and others (1983); the values were scaled to $\mu \mathrm{mol} / \mathrm{L}$. For some reason, some of the values in this appendix were transferred incorrectly from the original dataset to Pacheco and Van der Weijden (1996) and Pacheco (1998b). Some values regarding the cations (not shown in this appendix) are also incorrect in those papers, and the correct values are $(\mu \mathrm{mol} / \mathrm{L}): \mathrm{K}(215)=34, \operatorname{Mg}(226)=$ $65, \operatorname{Mg}(269)=861, \mathrm{Ca}(42)=107, \mathrm{Ca}(85)=171, \mathrm{Ca}(226)=131, \mathrm{Ca}(267)=$ $327, \mathrm{Ca}(271)=128$, and $\mathrm{Ca}(439)=157$, where values within brackets represent sample numbers. The chart shows prior and post assignments of samples to the $\mathrm{CA}$ and ClA groups. Prob-3/B is the sample's average posterior probability of group $3(\mathrm{CA})$ and group $\mathrm{B}(\mathrm{ClA})$ memberships (agriculture influence). 


\begin{tabular}{|c|c|c|c|c|c|c|c|c|c|c|c|c|}
\hline \multicolumn{3}{|c|}{ Identification } & \multicolumn{5}{|c|}{ Raw data } & \multicolumn{2}{|c|}{ CA/DA } & \multicolumn{2}{|c|}{$\mathrm{ClA} / \mathrm{DA}$} & \multirow[b]{2}{*}{ Prob-3/B } \\
\hline $\mathrm{nr}$ & $M(\mathrm{~m})$ & $P(\mathrm{~m})$ & {$\left[\mathrm{HCO}_{3}-\right.$} & $\left.{ }^{-}\right]\left[\mathrm{Cl}^{-}\right]$ & {$\left[\mathrm{SO}_{4}{ }^{2-}\right]$} & {$\left[\mathrm{NO}_{3}{ }^{-}\right]$} & {$\left[\mathrm{SiO}_{2}\right]$} & Prior & Post & Prior & Post & \\
\hline 28 & $2,53,614$ & $3,53,895$ & 780 & 440 & 356 & 371 & 656 & 3 & 1 & $\mathrm{C}$ & $\mathrm{C}$ & 0.21 \\
\hline 30 & $2,53,789$ & $3,53,965$ & 844 & 485 & 458 & 460 & 639 & 3 & 3 & $\mathrm{C}$ & $\mathrm{C}$ & 0.33 \\
\hline 31 & $2,53,263$ & $3,53,298$ & 490 & 423 & 185 & 387 & 506 & 3 & 3 & A & A & 0.27 \\
\hline 32 & $2,53,228$ & $3,53,579$ & 390 & 282 & 129 & 371 & 558 & 3 & 1 & A & A & 0.24 \\
\hline 35 & $2,52,491$ & $3,52,105$ & 729 & 347 & 341 & 221 & 614 & 1 & 1 & $\mathrm{C}$ & $\mathrm{C}$ & 0.13 \\
\hline 39 & $2,52,631$ & $3,54,666$ & 619 & 231 & 129 & 216 & 260 & 3 & 3 & A & $\mathrm{A}$ & 0.23 \\
\hline 41 & $2,51,789$ & $3,55,052$ & 261 & 189 & 198 & 55 & 463 & 1 & 1 & $\mathrm{~A}$ & $\mathrm{~A}$ & 0.12 \\
\hline 42 & $2,52,526$ & $3,55,754$ & 370 & 130 & 127 & 139 & 421 & 1 & 1 & A & $\mathrm{A}$ & 0.16 \\
\hline 45 & $2,54,526$ & $3,58,596$ & 1280 & 668 & 464 & 121 & 571 & 1 & 2 & $\mathrm{C}$ & $\mathrm{C}$ & 0.03 \\
\hline 51 & $2,53,474$ & $3,58,982$ & 780 & 499 & 458 & 189 & 100 & 2 & 2 & $\mathrm{C}$ & $\mathrm{C}$ & 0.06 \\
\hline 59 & $2,52,281$ & $3,58,526$ & 2260 & 2115 & 635 & 150 & 674 & 2 & 2 & B & $\mathrm{C}$ & 0.02 \\
\hline 60 & $2,53,614$ & $3,57,403$ & 560 & 248 & 158 & 63 & 524 & 1 & 1 & A & A & 0.05 \\
\hline 61 & $2,54,105$ & $3,57,684$ & 580 & 231 & 83 & 18 & 560 & 1 & 1 & A & $\mathrm{A}$ & 0.02 \\
\hline 63 & $2,53,754$ & $3,53,298$ & 229 & 790 & 735 & 998 & 399 & 3 & 3 & B & B & 1.00 \\
\hline 66 & $2,51,579$ & $3,53,719$ & 480 & 296 & 325 & 366 & 474 & 3 & 3 & A & A & 0.37 \\
\hline 67 & $2,51,754$ & $3,53,509$ & 1052 & 243 & 4 & 0 & 684 & 1 & 1 & $\mathrm{C}$ & $\mathrm{C}$ & 0.00 \\
\hline 71 & $2,50,526$ & $3,53,263$ & 639 & 183 & 433 & 0 & 626 & 1 & 1 & $\mathrm{C}$ & $\mathrm{C}$ & 0.07 \\
\hline 72 & $2,50,421$ & $3,52,947$ & 239 & 164 & 56 & 1 & 478 & 1 & 1 & A & A & 0.05 \\
\hline 74 & $2,49,930$ & $3,53,123$ & 660 & 149 & 44 & 32 & 609 & 1 & 1 & A & A & 0.02 \\
\hline 75 & $2,49,719$ & $3,52,772$ & 480 & 138 & 62 & 0 & 399 & 1 & 1 & A & A & 0.05 \\
\hline 76 & $2,49,754$ & $3,52,421$ & 810 & 155 & 92 & 0 & 503 & 1 & 1 & $\mathrm{C}$ & $\mathrm{C}$ & 0.02 \\
\hline 77 & $2,52,035$ & $3,52,140$ & 851 & 550 & 237 & 258 & 499 & 2 & 1 & $\mathrm{C}$ & $\mathrm{C}$ & 0.11 \\
\hline 78 & $2,51,474$ & $3,51,930$ & 918 & 1664 & 473 & 874 & 438 & 2 & 2 & B & B & 0.61 \\
\hline 79 & $2,50,737$ & $3,52,035$ & 410 & 181 & 125 & 121 & 634 & 1 & 1 & A & A & 0.05 \\
\hline 84 & $2,51,649$ & $3,53,158$ & 451 & 307 & 323 & 211 & 426 & 3 & 3 & A & $\mathrm{A}$ & 0.27 \\
\hline 85 & $2,51,579$ & $3,52,982$ & 590 & 169 & 94 & 82 & 606 & 1 & 1 & A & A & 0.03 \\
\hline 86 & $2,55,017$ & $3,53,403$ & 870 & 279 & 35 & 60 & 663 & 1 & 1 & $\mathrm{C}$ & $\mathrm{C}$ & 0.01 \\
\hline 87 & $2,56,316$ & $3,53,158$ & 451 & 243 & 177 & 1 & 613 & 1 & 1 & A & A & 0.03 \\
\hline 90 & $2,57,438$ & $3,55,474$ & 760 & 248 & 125 & 47 & 506 & 1 & 1 & $\mathrm{C}$ & A & 0.03 \\
\hline 92 & $2,58,000$ & $3,56,737$ & 580 & 186 & 117 & 0 & 552 & 1 & 1 & A & $\mathrm{A}$ & 0.03 \\
\hline 96 & $2,58,386$ & $3,55,228$ & 480 & 336 & 58 & 32 & 652 & 1 & 1 & A & A & 0.01 \\
\hline 99 & $2,59,123$ & $3,54,982$ & 600 & 567 & 366 & 37 & 353 & 2 & 2 & $\mathrm{C}$ & $\mathrm{C}$ & 0.06 \\
\hline 202 & $2,50,175$ & $3,55,017$ & 239 & 1297 & 1307 & 839 & 573 & 3 & 3 & B & B & 0.91 \\
\hline 203 & $2,50,210$ & $3,55,579$ & 610 & 372 & 417 & 185 & 440 & 2 & 3 & $\mathrm{C}$ & $\mathrm{C}$ & 0.23 \\
\hline 204 & $2,51,895$ & $3,56,807$ & 352 & 254 & 172 & 158 & 657 & 1 & 1 & A & A & 0.07 \\
\hline 205 & $2,52,561$ & $3,57,052$ & 716 & 536 & 404 & 379 & 485 & 3 & 3 & $\mathrm{C}$ & $\mathrm{C}$ & 0.30 \\
\hline 206 & $2,51,052$ & $3,56,281$ & 472 & 677 & 289 & 37 & 441 & 2 & 1 & $\mathrm{C}$ & A & 0.05 \\
\hline 207 & $2,50,421$ & $3,54,737$ & 244 & 621 & 580 & 500 & 489 & 3 & 3 & B & $\mathrm{C}$ & 0.50 \\
\hline 208 & $2,50,666$ & $3,55,298$ & 328 & 181 & 171 & 92 & 474 & 1 & 1 & A & A & 0.12 \\
\hline 209 & $2,50,456$ & $3,53,895$ & 367 & 231 & 323 & 240 & 532 & 3 & 3 & A & A & 0.28 \\
\hline 210 & $2,50,386$ & $3,53,368$ & 388 & 183 & 76 & 82 & 626 & 1 & 1 & A & A & 0.03 \\
\hline 211 & $2,51,789$ & $3,56,035$ & 1080 & 395 & 383 & 71 & 587 & 1 & 1 & $\mathrm{C}$ & $\mathrm{C}$ & 0.04 \\
\hline 212 & $2,51,930$ & $3,55,544$ & 357 & 85 & 173 & 144 & 603 & 1 & 1 & A & A & 0.10 \\
\hline 213 & $2,52,702$ & $3,56,351$ & 429 & 691 & 431 & 855 & 405 & 3 & 3 & B & B & 0.92 \\
\hline 214 & $2,52,351$ & $3,54,702$ & 215 & 220 & 437 & 203 & 437 & 3 & 3 & A & A & 0.38 \\
\hline 215 & $2,52,702$ & $3,54,877$ & 690 & 121 & 173 & 18 & 564 & 1 & 1 & $\mathrm{C}$ & $\mathrm{C}$ & 0.03 \\
\hline 216 & $2,50,245$ & $3,52,035$ & 1113 & 189 & 227 & 53 & 660 & 1 & 1 & $\mathrm{C}$ & $\mathrm{C}$ & 0.02 \\
\hline
\end{tabular}


Continued

\begin{tabular}{|c|c|c|c|c|c|c|c|c|c|c|c|c|}
\hline \multirow[b]{2}{*}{$\mathrm{nr}$} & \multicolumn{2}{|c|}{ Identification } & \multicolumn{5}{|c|}{ Raw data } & \multicolumn{2}{|c|}{ CA/DA } & \multicolumn{2}{|c|}{$\mathrm{ClA} / \mathrm{DA}$} & \multirow[b]{2}{*}{ Prob $-3 / B$} \\
\hline & $M(\mathrm{~m})$ & $P(\mathrm{~m})$ & {$\left[\mathrm{HCO}_{3}{ }^{-}\right]$} & {$\left[\mathrm{Cl}^{-}\right]$} & {$\left[\mathrm{SO}_{4}{ }^{2-}\right]$} & {$\left[\mathrm{NO}_{3}{ }^{-}\right]$} & {$\left[\mathrm{SiO}_{2}\right]$} & Prior & Post & Prior & Post & \\
\hline 217 & $2,51,298$ & $3,52,456$ & 787 & 243 & 90 & 3 & 654 & 1 & 1 & $\mathrm{C}$ & $\mathrm{C}$ & 0.01 \\
\hline 218 & $2,52,000$ & $3,53,754$ & 2994 & 485 & 228 & 181 & 635 & 1 & 1 & $\mathrm{C}$ & $\mathrm{C}$ & 0.00 \\
\hline 219 & $2,50,140$ & $3,54,561$ & 167 & 762 & 139 & 871 & 465 & 3 & 3 & B & A & 0.55 \\
\hline 220 & $2,53,403$ & $3,59,158$ & 3655 & 2482 & 1047 & 1081 & 264 & 2 & 2 & B & $\mathrm{B}$ & 0.50 \\
\hline 221 & $2,54,456$ & $3,57,438$ & 477 & 209 & 137 & 3 & 522 & 1 & 1 & A & $\mathrm{A}$ & 0.04 \\
\hline 222 & $2,53,544$ & $3,57,544$ & 642 & 259 & 194 & 216 & 634 & 1 & 1 & A & A & 0.08 \\
\hline 223 & $2,53,158$ & $3,56,947$ & 326 & 254 & 371 & 435 & 485 & 3 & 3 & A & A & 0.44 \\
\hline 224 & $2,53,509$ & $3,56,035$ & 1155 & 130 & 138 & 77 & 411 & 1 & 1 & $\mathrm{C}$ & $\mathrm{C}$ & 0.04 \\
\hline 225 & $2,53,263$ & $3,55,474$ & 372 & 133 & 227 & 58 & 472 & 1 & 1 & A & A & 0.13 \\
\hline 226 & $2,53,684$ & $3,55,579$ & 436 & 113 & 158 & 85 & 545 & 1 & 1 & A & $\mathrm{A}$ & 0.08 \\
\hline 227 & $2,53,965$ & $3,55,895$ & 367 & 124 & 154 & 226 & 581 & 1 & 1 & A & A & 0.15 \\
\hline 228 & $2,52,526$ & $3,52,245$ & 836 & 268 & 342 & 177 & 750 & 1 & 1 & $\mathrm{C}$ & $\mathrm{C}$ & 0.05 \\
\hline 229 & $2,55,684$ & $3,51,684$ & 557 & 536 & 162 & 205 & 666 & 1 & 1 & A & A & 0.04 \\
\hline 230 & $2,57,544$ & $3,52,456$ & 664 & 203 & 318 & 21 & 546 & 1 & 1 & $\mathrm{C}$ & $\mathrm{C}$ & 0.07 \\
\hline 231 & $2,55,193$ & $3,52,351$ & 626 & 178 & 448 & 124 & 508 & 1 & 1 & $\mathrm{C}$ & $\mathrm{C}$ & 0.22 \\
\hline 232 & $2,54,561$ & $3,53,333$ & 334 & 175 & 81 & 435 & 745 & 3 & 1 & A & A & 0.17 \\
\hline 233 & $2,54,456$ & $3,53,965$ & 690 & 790 & 514 & 2903 & 687 & 3 & 3 & B & B & 1.00 \\
\hline 234 & $2,53,579$ & $3,54,807$ & 433 & 158 & 278 & 132 & 670 & 1 & 1 & A & $\mathrm{A}$ & 0.09 \\
\hline 235 & $2,55,403$ & $3,56,947$ & 523 & 155 & 70 & 65 & 668 & 1 & 1 & A & A & 0.02 \\
\hline 236 & $2,55,649$ & $3,57,088$ & 601 & 1354 & 1144 & 1387 & 586 & 3 & 3 & B & B & 0.99 \\
\hline 237 & $2,54,877$ & $3,56,175$ & 400 & 118 & 96 & 248 & 207 & 3 & 3 & A & A & 0.35 \\
\hline 238 & $2,55,158$ & $3,56,386$ & 438 & 141 & 135 & 68 & 535 & 1 & 1 & A & A & 0.06 \\
\hline 239 & $2,54,772$ & $3,55,193$ & 600 & 324 & 274 & 500 & 558 & 3 & 3 & A & A & 0.38 \\
\hline 241 & $2,60,210$ & $3,57,193$ & 231 & 79 & 24 & 61 & 514 & 1 & 1 & A & A & 0.06 \\
\hline 242 & $2,59,754$ & $3,57,509$ & 136 & 65 & 10 & 71 & 445 & 1 & 1 & A & A & 0.09 \\
\hline 243 & $2,54,105$ & $3,59,333$ & 1529 & 874 & 515 & 435 & 776 & 2 & 1 & $\mathrm{C}$ & $\mathrm{C}$ & 0.07 \\
\hline 244 & $2,55,859$ & $3,55,824$ & 323 & 265 & 336 & 250 & 476 & 3 & 3 & A & A & 0.33 \\
\hline 245 & $2,54,912$ & $3,54,702$ & 692 & 310 & 173 & 131 & 608 & 1 & 1 & A & $\mathrm{C}$ & 0.04 \\
\hline 246 & $2,54,631$ & $3,56,351$ & 564 & 127 & 151 & 131 & 519 & 1 & 1 & A & A & 0.09 \\
\hline 247 & $2,54,947$ & $3,57,193$ & 454 & 282 & 372 & 166 & 532 & 3 & 1 & A & $\mathrm{C}$ & 0.21 \\
\hline 248 & $2,50,596$ & $3,55,789$ & 526 & 195 & 384 & 500 & 415 & 3 & 3 & A & $\mathrm{C}$ & 0.47 \\
\hline 249 & $2,48,877$ & $3,52,947$ & 408 & 107 & 170 & 52 & 560 & 1 & 1 & A & A & 0.06 \\
\hline 250 & $2,58,561$ & $3,57,614$ & 187 & 268 & 279 & 324 & 579 & 3 & 3 & A & A & 0.32 \\
\hline 251 & $2,58,842$ & $3,57,368$ & 203 & 93 & 15 & 35 & 467 & 1 & 1 & A & A & 0.06 \\
\hline 252 & $2,59,088$ & $3,56,842$ & 128 & 104 & 7 & 66 & 414 & 1 & 1 & A & A & 0.10 \\
\hline 253 & $2,59,438$ & $3,56,175$ & 249 & 90 & 66 & 61 & 619 & 1 & 1 & A & A & 0.04 \\
\hline 254 & $2,60,000$ & $3,55,509$ & 295 & 116 & 75 & 29 & 600 & 1 & 1 & A & A & 0.03 \\
\hline 255 & $2,60,105$ & $3,55,509$ & 293 & 124 & 72 & 66 & 672 & 1 & 1 & A & A & 0.03 \\
\hline 256 & $2,59,614$ & $3,56,140$ & 236 & 130 & 75 & 35 & 520 & 1 & 1 & A & A & 0.06 \\
\hline 257 & $2,59,438$ & $3,55,930$ & 243 & 144 & 99 & 140 & 613 & 1 & 1 & A & A & 0.07 \\
\hline 258 & $2,59,193$ & $3,56,000$ & 59 & 96 & 9 & 66 & 237 & 1 & 1 & $\mathrm{~A}$ & A & 0.21 \\
\hline 259 & $2,58,456$ & $3,53,824$ & 723 & 262 & 173 & 190 & 740 & 1 & 1 & A & $\mathrm{C}$ & 0.03 \\
\hline 260 & $2,55,403$ & $3,53,438$ & 647 & 141 & 62 & 44 & 760 & 1 & 1 & A & A & 0.01 \\
\hline 261 & $2,56,140$ & $3,53,965$ & 675 & 931 & 365 & 452 & 620 & 2 & 1 & $\mathrm{C}$ & $\mathrm{C}$ & 0.21 \\
\hline 262 & $2,56,035$ & $3,54,070$ & 1047 & 3328 & 749 & 1516 & 617 & 2 & 2 & B & B & 0.51 \\
\hline 263 & $2,56,105$ & $3,54,281$ & 1721 & 3159 & 1450 & 1242 & 740 & 2 & 2 & B & B & 0.50 \\
\hline 264 & $2,55,930$ & $3,54,737$ & 451 & 333 & 204 & 250 & 550 & 3 & 1 & A & A & 0.16 \\
\hline
\end{tabular}


Continued

\begin{tabular}{|c|c|c|c|c|c|c|c|c|c|c|c|c|}
\hline \multirow[b]{2}{*}{$\mathrm{nr}$} & \multicolumn{2}{|c|}{ Identification } & \multicolumn{5}{|c|}{ Raw data } & \multicolumn{2}{|c|}{$\mathrm{CA} / \mathrm{DA}$} & \multicolumn{2}{|c|}{$\mathrm{ClA} / \mathrm{DA}$} & \multirow[b]{2}{*}{ Prob-3/B } \\
\hline & $M(\mathrm{~m})$ & $P(\mathrm{~m})$ & {$\left[\mathrm{HCO}_{3}\right]$} & - $\left[\mathrm{Cl}^{-}\right]$ & {$\left[\mathrm{SO}_{4}{ }^{2-}\right]$} & {$\left[\mathrm{NO}_{3}{ }^{-}\right]$} & {$\left[\mathrm{SiO}_{2}\right]$} & Prior & Post & Prior & Post & \\
\hline 265 & $2,56,000$ & $3,54,526$ & 567 & 152 & 43 & 9 & 697 & 1 & 1 & A & A & 0.01 \\
\hline 266 & $2,56,000$ & $3,55,052$ & 533 & 1297 & 1784 & 532 & 486 & 2 & 2 & B & $\mathrm{B}$ & 0.54 \\
\hline 267 & $2,56,456$ & $3,54,877$ & 1278 & 564 & 113 & 182 & 739 & 1 & 1 & $\mathrm{C}$ & $\mathrm{C}$ & 0.01 \\
\hline 268 & $2,56,526$ & $3,55,263$ & 526 & 527 & 439 & 282 & 581 & 2 & 3 & $\mathrm{C}$ & $\mathrm{C}$ & 0.25 \\
\hline 269 & $2,56,316$ & $3,54,105$ & 877 & 6770 & 1117 & 1048 & 567 & 2 & 2 & B & B & 0.50 \\
\hline 270 & $2,57,088$ & $3,54,702$ & 1169 & 1326 & 675 & 726 & 452 & 2 & 2 & B & $\mathrm{B}$ & 0.58 \\
\hline 271 & $2,57,754$ & $3,54,386$ & 449 & 214 & 50 & 139 & 842 & 1 & 1 & $\mathrm{~A}$ & A & 0.01 \\
\hline 272 & $2,57,158$ & $3,53,789$ & 367 & 259 & 12 & 187 & 573 & 1 & 1 & A & A & 0.06 \\
\hline 273 & $2,52,877$ & $3,51,684$ & 652 & 164 & 24 & 4 & 723 & 1 & 1 & A & A & 0.01 \\
\hline 274 & $2,55,930$ & $3,52,631$ & 470 & 305 & 105 & 150 & 530 & 1 & 1 & A & A & 0.07 \\
\hline 275 & $2,56,316$ & $3,52,316$ & 516 & 282 & 25 & 105 & 662 & 1 & 1 & A & A & 0.02 \\
\hline 276 & $2,56,737$ & $3,51,895$ & 531 & 480 & 71 & 176 & 615 & 1 & 1 & A & A & 0.03 \\
\hline 277 & $2,56,877$ & $3,52,596$ & 606 & 361 & 119 & 113 & 736 & 1 & 1 & A & A & 0.02 \\
\hline 278 & $2,57,965$ & $3,52,210$ & 375 & 203 & 37 & 113 & 760 & 1 & 1 & A & A & 0.02 \\
\hline 279 & $2,58,526$ & $3,52,631$ & 688 & 592 & 134 & 118 & 692 & 1 & 1 & $\mathrm{C}$ & A & 0.01 \\
\hline 280 & $2,59,614$ & $3,50,912$ & 434 & 152 & 23 & 13 & 583 & 1 & 1 & A & A & 0.02 \\
\hline 402 & $2,56,631$ & $3,50,421$ & 150 & 115 & 14 & 22 & 211 & 1 & 1 & A & A & 0.16 \\
\hline 404 & $2,56,982$ & $3,50,526$ & 308 & 188 & 19 & 32 & 399 & 1 & 1 & A & A & 0.06 \\
\hline 406 & $2,54,281$ & $3,59,684$ & 853 & 623 & 151 & 60 & 692 & 1 & 1 & $\mathrm{C}$ & $\mathrm{C}$ & 0.01 \\
\hline 407 & $2,54,807$ & $3,59,474$ & 2081 & 745 & 399 & 106 & 757 & 1 & 1 & $\mathrm{C}$ & $\mathrm{C}$ & 0.00 \\
\hline 408 & $2,57,088$ & $3,59,052$ & 551 & 268 & 140 & 113 & 711 & 1 & 1 & A & A & 0.02 \\
\hline 410 & $2,60,666$ & $3,54,386$ & 272 & 107 & 25 & 74 & 530 & 1 & 1 & A & A & 0.05 \\
\hline 411 & $2,61,333$ & $3,53,579$ & 214 & 199 & 93 & 30 & 209 & 1 & 1 & A & A & 0.18 \\
\hline 415 & $2,48,631$ & $3,55,824$ & 470 & 244 & 34 & 8 & 612 & 1 & 1 & A & A & 0.01 \\
\hline 420 & $2,54,702$ & $3,50,947$ & 390 & 209 & 46 & 14 & 340 & 1 & 1 & A & A & 0.07 \\
\hline 421 & $2,55,859$ & $3,50,842$ & 353 & 188 & 45 & 23 & 339 & 1 & 1 & A & A & 0.08 \\
\hline 423 & $2,60,421$ & $3,54,245$ & 262 & 88 & 32 & 29 & 352 & 1 & 1 & A & A & 0.10 \\
\hline 424 & $2,58,596$ & $3,51,298$ & 365 & 232 & 79 & 81 & 445 & 1 & 1 & A & A & 0.08 \\
\hline 425 & $2,58,596$ & $3,51,088$ & 819 & 91 & 21 & 11 & 812 & 1 & 1 & $\mathrm{C}$ & $\mathrm{C}$ & 0.00 \\
\hline 427 & $2,59,649$ & $3,51,333$ & 433 & 162 & 10 & 30 & 534 & 1 & 1 & A & A & 0.03 \\
\hline 430 & $2,48,702$ & $3,57,017$ & 725 & 241 & 324 & 34 & 464 & 1 & 1 & $\mathrm{C}$ & $\mathrm{C}$ & 0.09 \\
\hline 432 & $2,60,596$ & $3,52,807$ & 338 & 161 & 19 & 25 & 689 & 1 & 1 & A & A & 0.01 \\
\hline 433 & $2,60,386$ & $3,52,351$ & 280 & 107 & 82 & 24 & 524 & 1 & 1 & A & A & 0.05 \\
\hline 434 & $2,60,772$ & $3,52,456$ & 292 & 79 & 16 & 13 & 524 & 1 & 1 & A & A & 0.03 \\
\hline 435 & $2,60,456$ & $3,51,859$ & 421 & 64 & 10 & 5 & 581 & 1 & 1 & A & A & 0.02 \\
\hline 438 & $2,56,035$ & $3,59,298$ & 430 & 152 & 60 & 30 & 487 & 1 & 1 & A & A & 0.04 \\
\hline 439 & $2,53,719$ & $3,51,474$ & 714 & 128 & 25 & 0 & 709 & 1 & 1 & A & A & 0.01 \\
\hline 440 & $2,54,140$ & $3,51,228$ & 636 & 127 & 58 & 7 & 729 & 1 & 1 & A & A & 0.01 \\
\hline 441 & $2,56,702$ & $3,51,298$ & 956 & 166 & 67 & 8 & 875 & 1 & 1 & $\mathrm{C}$ & $\mathrm{C}$ & 0.00 \\
\hline 442 & $2,58,561$ & $3,52,175$ & 607 & 832 & 50 & 75 & 838 & 1 & 1 & $\mathrm{C}$ & A & 0.00 \\
\hline 443 & $2,59,649$ & $3,54,386$ & 549 & 378 & 65 & 33 & 569 & 1 & 1 & A & A & 0.02 \\
\hline 444 & $2,59,649$ & $3,53,333$ & 351 & 157 & 27 & 36 & 442 & 1 & 1 & A & A & 0.05 \\
\hline 446 & $2,56,526$ & $3,54,175$ & 651 & 255 & 28 & 33 & 887 & 1 & 1 & A & A & 0.00 \\
\hline 447 & $2,56,105$ & $3,53,438$ & 974 & 533 & 189 & 107 & 548 & 1 & 1 & $\mathrm{C}$ & $\mathrm{C}$ & 0.02 \\
\hline 452 & $2,52,631$ & $3,52,281$ & 838 & 338 & 351 & 105 & 774 & 1 & 1 & $\mathrm{C}$ & $\mathrm{C}$ & 0.03 \\
\hline 453 & $2,51,579$ & $3,54,386$ & 1123 & 276 & 92 & 17 & 752 & 1 & 1 & $\mathrm{C}$ & $\mathrm{C}$ & 0.00 \\
\hline 457 & $2,50,666$ & $3,50,631$ & 566 & 93 & 3 & 1 & 568 & 1 & 1 & A & A & 0.02 \\
\hline
\end{tabular}


Continued

\begin{tabular}{|c|c|c|c|c|c|c|c|c|c|c|c|c|}
\hline \multirow[b]{2}{*}{$\mathrm{nr}$} & \multicolumn{2}{|c|}{ Identification } & \multicolumn{5}{|c|}{ Raw data } & \multicolumn{2}{|c|}{$\mathrm{CA} / \mathrm{DA}$} & \multicolumn{2}{|c|}{$\mathrm{ClA} / \mathrm{DA}$} & \multirow[b]{2}{*}{ Prob-3/E } \\
\hline & $M(\mathrm{~m})$ & $P(\mathrm{~m})$ & {$\left[\mathrm{HCO}_{3}{ }^{-}\right]$} & ] $\left[\mathrm{Cl}^{-}\right]$ & {$\left[\mathrm{SO}_{4}{ }^{2-}\right]$} & {$\left[\mathrm{NO}_{3}{ }^{-}\right]$} & {$\left[\mathrm{SiO}_{2}\right]$} & Prior & Post & Prior & Post & \\
\hline 458 & 255509 & 351438 & 526 & 195 & 18 & 22 & 670 & 1 & 1 & A & A & 0.01 \\
\hline 463 & 248947 & 350386 & 231 & 241 & 67 & 31 & 366 & 1 & 1 & A & A & 0.09 \\
\hline 514 & 254737 & 356035 & 558 & 161 & 133 & 27 & 497 & 1 & 1 & A & A & 0.05 \\
\hline 522 & 253824 & 356281 & 1149 & 181 & 95 & 32 & 600 & 1 & 1 & $\mathrm{C}$ & $\mathrm{C}$ & 0.01 \\
\hline 523 & 252702 & 353579 & 650 & 302 & 299 & 34 & 860 & 1 & 1 & $\mathrm{C}$ & $\mathrm{C}$ & 0.01 \\
\hline 524 & $2,52,842$ & $3,54,982$ & 918 & 248 & 228 & 21 & 679 & 1 & 1 & $\mathrm{C}$ & $\mathrm{C}$ & 0.01 \\
\hline 525 & $2,51,754$ & $3,55,649$ & 503 & 126 & 138 & 48 & 554 & 1 & 1 & A & A & 0.05 \\
\hline 530 & $2,56,140$ & $3,53,614$ & 643 & 454 & 356 & 62 & 742 & 1 & 1 & $\mathrm{C}$ & $\mathrm{C}$ & 0.03 \\
\hline 534 & $2,57,509$ & $3,53,123$ & 310 & 277 & 162 & 100 & 604 & 1 & 1 & A & A & 0.06 \\
\hline 535 & $2,57,754$ & $3,52,281$ & 625 & 725 & 286 & 105 & 568 & 2 & 1 & $\mathrm{C}$ & $\mathrm{C}$ & 0.04 \\
\hline 536 & $2,55,824$ & $3,51,719$ & 529 & 236 & 111 & 42 & 431 & 1 & 1 & A & A & 0.06 \\
\hline 539 & $2,57,509$ & $3,54,912$ & 600 & 685 & 226 & 150 & 375 & 2 & 1 & $\mathrm{C}$ & A & 0.08 \\
\hline 540 & $2,56,491$ & $3,54,105$ & 520 & 224 & 46 & 63 & 806 & 1 & 1 & A & A & 0.01 \\
\hline 573 & $2,59,298$ & $3,55,789$ & 96 & 195 & 20 & 19 & 280 & 1 & 1 & A & A & 0.13 \\
\hline 574 & $2,58,561$ & $3,56,105$ & 652 & 914 & 189 & 29 & 515 & 2 & 1 & $\mathrm{C}$ & A & 0.01 \\
\hline 575 & $2,58,842$ & $3,55,193$ & 875 & 426 & 261 & 30 & 514 & 1 & 1 & $\mathrm{C}$ & $\mathrm{C}$ & 0.03 \\
\hline 583 & $2,48,947$ & $3,57,895$ & 305 & 2350 & 269 & 284 & 415 & 2 & 2 & B & A & 0.19 \\
\hline 589 & $2,56,316$ & $3,52,316$ & 501 & 205 & 39 & 24 & 679 & 1 & 1 & A & A & 0.01 \\
\hline 591 & $2,50,421$ & $3,57,403$ & 572 & 412 & 418 & 20 & 228 & 2 & 2 & $\mathrm{C}$ & $\mathrm{C}$ & 0.08 \\
\hline
\end{tabular}

